\title{
A Comparative Analysis of Relationship Between Innovation and Transport Sector Carbon Emissions in Developed and Developing Mediterranean Countries
}

Nigar Demircan Çakar

Düzce Üniversitesi: Duzce Universitesi

Ayfer Gedikli ( $\square$ ayfergedikli@yahoo.com )

Duzce University: Duzce Universitesi https://orcid.org/0000-0002-7128-1976

\section{Seyfettin Erdoğan}

Istanbul Medeniyet Universitesi

\section{Durmuş Çağrı Yııdırım}

Tekirdag Namik Kemal Universitesi

\section{Research Article}

Keywords: Innovation, Transport Sector, Carbon emissions, Mediterranean Countries, PANIC, Panel Cointegration, FMOLS DOLS

Posted Date: February 18th, 2021

DOI: https://doi.org/10.21203/rs.3.rs-206436/v1

License: (c) (1) This work is licensed under a Creative Commons Attribution 4.0 International License. Read Full License

Version of Record: A version of this preprint was published at Environmental Science and Pollution Research on April 20th, 2021. See the published version at https://doi.org/10.1007/s11356-021-13390-y. 


\author{
Prof. Dr. Nigar Demircan Çakar \\ Düzce University, Faculty of Business Administration \\ nigarcakar@duzce.edu.tr. \\ ORCID: 0000-0002-7878-9123
}

\author{
Prof. Dr. Ayfer Gedikli \\ Düzce University, Faculty of Political Sciences, Department of Economics \\ ayfergedikli@yahoo.com \\ ORCID: 0000-0002-7128-1976 \\ ayfergedikli@yahoo.com
}

\author{
Assoc. Prof. Dr. Durmuş Çağrı Yıldırım \\ Namık Kemal University \\ Faculty of Economics and Administrative Sciences, Department of Economics \\ cyildirim81@gmail.com \\ 0000-0003-4168-2792
}

ty, Faculty of Political Sciences, Department of Economics ORCID: 0000-0003-2790-4221

Abstract

Innovation technologies have been recognized as an efficient solution to alleviate carbon emissions stem from transport sector. The aim of this study is to investigate the impact of innovation on carbon emissions stemming from the transportation sector in the Mediterranean countries. Based on the available data, Albania, Algeria, Bosnia and Herzegovina, Croatia, Egypt, Morocco, Tunisia, and Turkey are selected as the 8 developing countries; and Cyprus, France, Greece, Israel, Italy, Spain are selected as the 6 developed countries and included in the analysis. Due to data constraints, the analysis period has been determined as 1997-2017 for the developing Mediterranean countries, and 2003-2017 for the developed Mediterranean countries. After determining the long-term relationship with the panel cointegration method, we obtained the long-term coefficients with FMOLS and DOLS methods. The empirical test results indicated that the increments in the level of innovation in developing countries have a negative impact on carbon emissions due to transportation if the innovation results from an increase in patents. However, the trademark increase does not have a statistically significant effect on carbon emissions. In developed countries, it is observed that both the patent application increases and the trademark increases have a positive effect on carbon emissions.

Key Words: Innovation, Transport Sector, Carbon emissions, Mediterranean Countries, PANIC, Panel Co-integration, FMOLS DOLS 


\section{A Comparative Analysis of Relationship between Innovation and Transport Sector Carbon Emissions in Developed and Developing Mediterranean Countries}

\section{INTRODUCTION}

Since the Rio Declaration on Environment and Development, and the Statement of principles for the Sustainable Management of Forests were accepted by more than 178 Governments at the United Nations Conference on Environment and Development (UNCED) in June 1992, innovation processes toward sustainable development (eco-innovations) have received increasing attention in different sectors. This raises the question "how to promote innovation technologies to reach sustainable environment targets without sacrificing growth and performance in different sectors?"

As a fundamental approach, there are two alternative ways to increase output. One should either increase the inputs for the production process, or "new ways" in which to get more output with the same amount of input (Rosenberg, 2004:1). "New ways" can be categorized under three forms (Broughel and Thierer, 2019:5): (1) cost reduction, (2) quality improvement, (3) new production methods as well as alternative goods and services. Schumpeter (2000) defined innovation as "the introduction of new technical methods, products, sources of supply, and forms of industrial organization". Roger (1983) described innovation as an idea, object, or practice that can be accepted as new by the people.

In the literature, there are many studies pointing to the spillover effect of innovation and technology on economic growth. Ulku (2004) investigated the relationship between innovation and economic growth in 20 OECD and 10 non-OECD countries over the period 1981-1997. The empirical results provided evidence of a positive relationship between innovation and per capita GDP in both OECD and non-OECD countries. The author also pointed out that the effect of $R \& D$ stock on innovation was significant only in the large markets of OECD countries. Pece, Simona, and Salisteanu (2015) analyzed the effects of innovation on the economic growth in Poland, the Czech Republic, and Hungary. The empirical results showed that there is a positive relationship between economic growth and innovation. Innovation and R\&D provide competitiveness, progress, and finally economic growth. Maradana et al. (2017) also found bidirectional causality between innovation and economic growth for 19 European countries spanning the period 1989-2014. Hence, according to the findings of many studies in the related literature, there is a close and bidirectional relationship between innovation and economic growth.

Since innovation technologies are improved for sustainable economic growth and sustainable environment, they can also be used in transport and energy sector. Actually, innovation is one of the key factors to control the spurring of the rise in $\mathrm{CO}_{2}$ emissions and there has been an outcry for innovative technologies. To combat environmental pollution due to $\mathrm{CO}_{2}$ emissions stem from transport, new innovative technologies have been developed and patented in the last decade (Mensah et al., 2018). Efficiency, intensity, and technology of vehicles are highly effective on the level of pollution and environment quality (Goulias, 2007: 66). Indeed, innovative technologies in the energy sector may bring less consumption, lower energy cost, more efficiency, higher quality of the environment as well as economic growth. Due to the 
improvements in the energy efficiency technologies, electrification, and applying more environment-friendly energy resources, global transport emissions rose by less than $0.5 \%$. Comparing with the annual increase of $1.9 \%$ since 2000, this rate of increase is promising (Teter, Tattini and Petropoulos, 2020). A remarkable reduction in fuel per kilometer around the world in the upcoming years can be possible by innovative technologies and hybridization. However, strong policies are needed to ensure maximum efficiency in automotive technology to transfer their benefit into fuel economy improvement. It is a fact that changing traditional pollutive transport technologies will require to adopt environmentfriendly innovative technologies. The development of innovative and high-performance technologies in the transportation sector will provide fine tuning of the design of transportation equipment (IEA, 2009a: 35).

Transportation is one of the most important determinants of economic activities and our daily life. Nevertheless, the transport sector has been facing economic, technological, and environmental challenges. Parallel to the increasing population and economic needs, there has been an exponential increase in conventional fuel use in the transport sector. Hence, the negative impacts of oil are increasing faster than ever. The transportation sector which includes the movement of people and goods by cars, trains, airplanes, and other vehicles is now one of the major sources of global warming and air pollution. The greatest proportion of greenhouse gas emissions belongs to carbon dioxide $\left(\mathrm{CO}_{2}\right)$ emissions resulting from the combustion of fossil-fuel-based products in the transport sector. There are certain reasons for increasing $\mathrm{CO}_{2}$ emissions in the transport sector: The most important reason is that in all cities, particularly in the metropolis, there is growing congestion. Congestion increases especially in rush hours due to staying in the traffic and exhausting more gas and carbon emissions. And since the transport is highly dependent on oil which is a non-renewable energy source, there is an increasing rate of air pollution. Moreover, cities are getting larger and the landscapes of cities are changing. In many countries, the instruction sector is one of the locomotive sectors. Urban transformation, constructing new buildings, and high-rises lead to the dramatic degradation of urban landscapes. Constructing new towns increases the need for new roads and transport facilities which cause the demolition of historical buildings and reductions in open space and green areas. And also, constructing new places and decentralization of cities caused longer trips with more vehicles. This also leads to higher dependence on cars rather than short trips with public transportation. Finally, globalization affected many sectors such as tourism, aviation, and international trade. Through multinational corporations, there are great industrial investments all over the world. These corporations initiated new patterns of distribution of goods/products which causes dramatic increases in global, regional, and local transportation activities (Banister, 2005: 16-17). Similarly, globalization motivated the tourism and aviation sectors which resulted in more transportation and more carbon emissions.

Starting from the beginning of the 1900s, conventional fossil fuel has been used extensively in the transport industry. Excessive use of fossil fuels in the transport sector causes pollution and environmental degradation. The largest sources of transportation-based greenhouse emissions are passenger cars and light-duty trucks which represent more than half of the 
emissions from this sector. The other half of greenhouse gas emissions from the transportation sector comes from commercial aircraft, ships, boats, train, and pipelines (EPA, 2019). Numerically, transport accounts for almost $16,2 \%$ of global energy use and $\mathrm{CO}_{2}$ emissions. Therefore, transport is responsible for both direct emissions from fossil fuels to power transport vehicles and indirect emissions through electricity. In total transport, road transport has a share of $11,9 \%$. Road trucks include cars, buses, and motorcycles (this group represents $60 \%$ of total road trucks) and trucks and lorries. Aviation is also responsible for the carbon emissions from domestic (40\%) and international aviation (60\%) (Ritchie and Roser, 2020). Besides, parallel to the increasing demand for modern highways, infrastructure constructions affect the land surface dramatically and cause great losses on habitat and biodiversity. The transportation sector is also one of the basic causes of air pollution-related death and disease such as cancer, asthma, bronchitis, etc. (Rowland et al., 1998: 10). Figure 1 illustrates the global transport sector's carbon emission trends over the period 2000-2019. World total $\mathrm{CO}_{2}$ emissions steadily increase from 5,8 Gt in 2000 to 8,2 Gt in 2019. Comparing with the shipping and aviation sectors, passenger road vehicles and road freight vehicles contributed more to total $\mathrm{CO}_{2}$ emissions.

Figure 1. Global Transport Sector Carbon Emissions (Gt, 2000-2019)

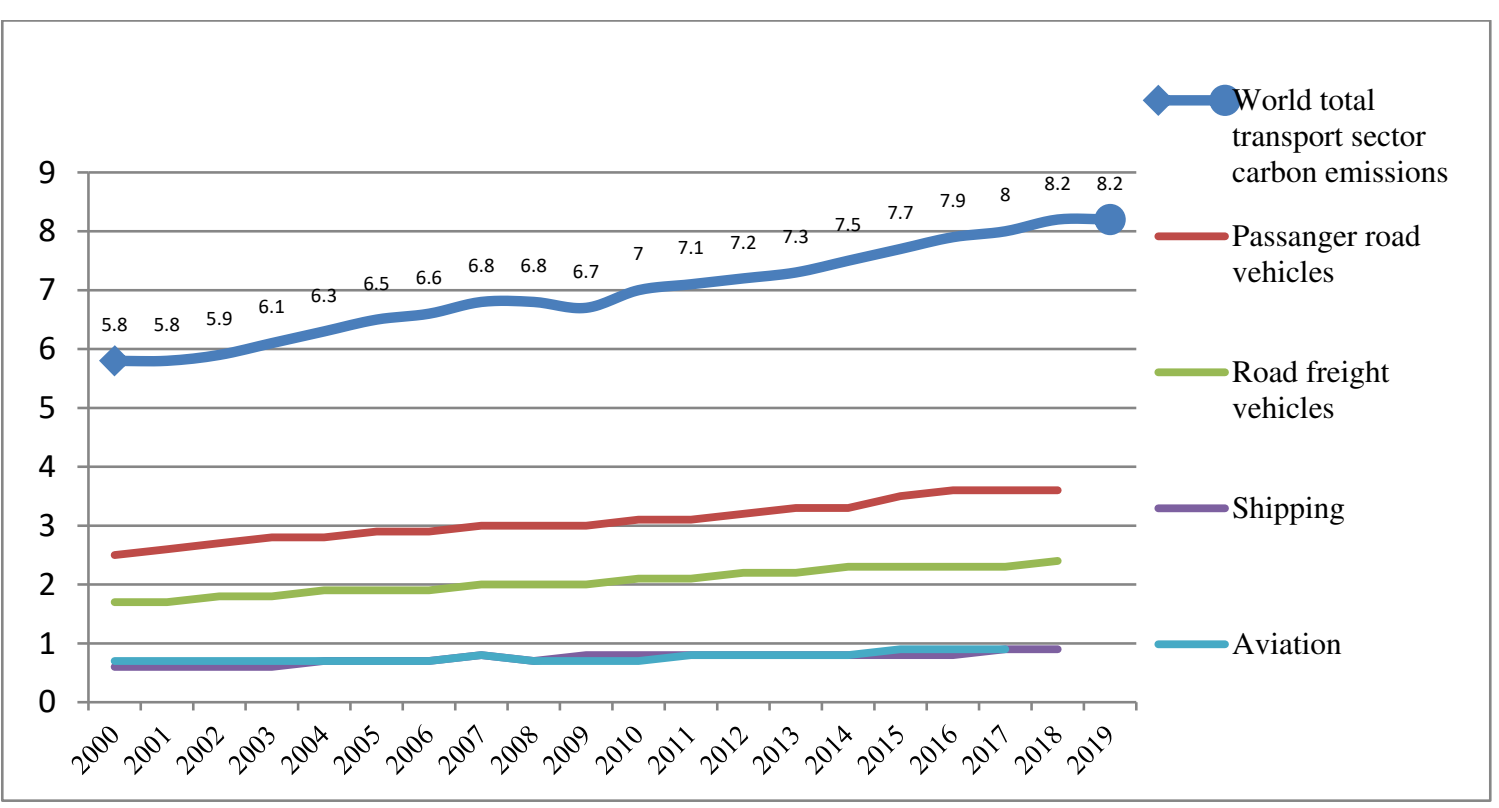

Source: Teter, Tattini and Petropoulos (2020); IEA (2019b)

IEA (2009a) reported that transport is responsible for one-quarter of global energy-related $\mathrm{CO}_{2}$ emissions. However, in 2019, the global transport sector energy intensity that is calculated by total energy consumption per unit of GDP fell by $2.3 \%$ (Teter, Tattini and Petropoulos, 2020). Besides, Covid-19 pandemic adversely affected the transportation sector. Until the Covid-19 pandemic started in the early days of 2020, $\mathrm{CO}_{2}$ emissions were rising around 1\% every year in the last ten years (Le Quéré et. al., 2020:647). Due to global lockdown precautions, $57 \%$ of global oil demand declined. Sharp declines in energy demand 
in 2020:Q1 led to a 5\% fall compared with 2019:Q1 in global carbon emissions. Road transport declined between 50\% and 75\%. At the end of March 2020, the global transport activity fell by $50 \%$ of the 2019 level. Indeed, $\mathrm{CO}_{2}$ emissions dropped more than energy demand since the greatest carbon-incentive fuels had the largest drops in demand during this period. The regions which experienced the earliest impacts of the Covid-19 had the largest $\mathrm{CO}_{2}$ emissions falls. It is also expected that the global lockdown will cause sharp declines in the global $\mathrm{CO}_{2}$ emissions and will be recorded as $30,6 \mathrm{Gt}$ by the end of this year. This amount is approximately $8 \%$ lower than the previous year (IEA, 2020a; IEA, 2020c). However, once the pandemic is over, there may be even more $\mathrm{CO}_{2}$ emissions in all sectors starting from the transport. Road vehicles such as cars, trucks, buses, and other motor vehicles are responsible for $3 / 4$ of transport $\mathrm{CO}_{2}$ emissions. Moreover, carbon emissions from aviation and shipping are rising which points out the necessity to have international cooperation and initiating global policies (Teter, Tattini and Petropoulos, 2020). IEA (2009b) predicted that unless there are international cooperation and global measures, worldwide car ownership will be triple to more than 2 billion; the trucking sector will be expected to be double and aviation will increase by fourfold by 2050. These increases in all subsectors of transportation will double the transport energy use that will bring higher rates of $\mathrm{CO}_{2}$ emissions. Indeed, transport energy use and $\mathrm{CO}_{2}$ emissions are estimated to increase by $50 \%$ by 2030 , and more than $80 \%$ by 2050 (IEA, 2009a: 29, 35).

Figure 2 represents the carbon emissions of Mediterranean countries. We included Israel, Italy, France, Spain, Greece, and Cyprus as developed Mediterranean countries; Turkey, Albania, Bosnia and Herzegovina, Croatia, Algeria, Tunisia, and Morocco as developing Mediterranean countries to our study. During the 2000-2016 period, carbon emissions of developed countries were always higher. However, starting from 2010, while developing Mediterranean countries' carbon emissions were rising, carbon emissions of developed Mediterranean countries started to decline. The decrease in carbon emissions in developed Mediterranean countries can be due to increasing energy efficiency and innovative technologies in the energy sector.

Figure 2. Developed and Developing Mediterranean Countries Carbon Emissions from the Transportation Sector (million tones, 2000-2016)

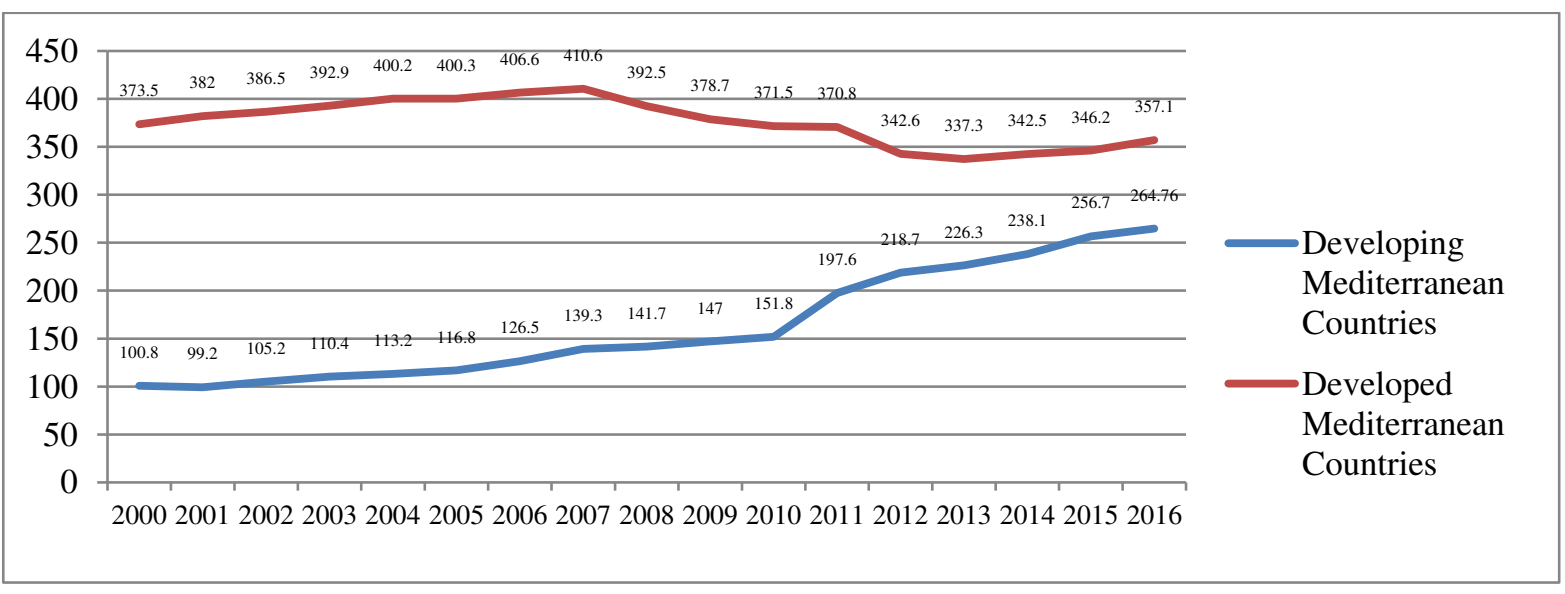

Source: Authors' own calculations from Ritchie and Roser (2020) 
Developing Mediterranean Countries: Turkey, Albania, Bosnia and Herzegovina, Croatia, Algeria, Tunisia, and Morocco Developed Mediterranean Countries: Israel, Italy, France, Spain, Greece, Cyprus

Figure 3. Developed and Developing Mediterranean Countries Carbon Emissions from Transport (Road and Shipping-Aviation) (2017, million tones)

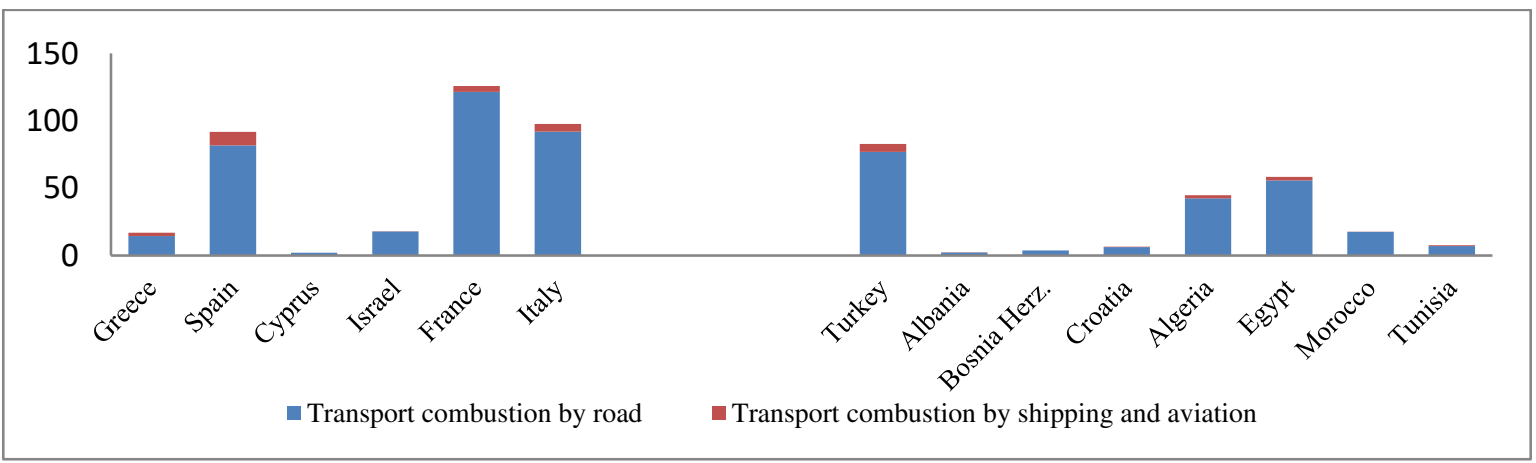

Source: IEA (2019a)

Figure 3 illustrates the carbon emissions of the transport subsectors in developed and developing Mediterranean countries in 2017. According to Figure 3, transport combustion by road is much higher than transport combustion by shipping and aviation both in developed and developing Mediterranean countries.

Although historically, there has been a close relationship between economic growth and transportation, there is a tradeoff between economic growth, transport increase, and environmental degradation. The question is whether we can initiate sustainable economic growth with less $\mathrm{CO}_{2}$ emissions. Moreover, to avoid the disastrous effect of climate change, global $\mathrm{CO}_{2}$ emissions must be decreased at least by $50 \%$. To reach this target, transport will have a crucial position. Even though there are huge cuts in $\mathrm{CO}_{2}$ in all other sectors, unless transport does not reduce $\mathrm{CO}_{2}$ emissions by 2050, it will be impossible to meet the target (IEA, 2009a: 29).

Transport sector is one of the leading sectors contributing to carbon emissions on a global scale. Transport sector is also one of the pioneer sectors which have the greatest technological developments. The most important contribution of innovation to the transport sector is energy efficiency improvements and technologies which reduce fuel consumption. Many studies have pointed out that innovation in the transport sector not only provide energy efficiency but also increases the service life of vehicles. Besides, the gains in efficiency of energy consumption lead reduction in the per unit price of energy services. This causes increases in the energy consumption and carbon emissions (the re-bound effect). In their studies, Greening, Greene, and Difiglio (2000); Herring and Roy (2007); Jin, Duan and Tang (2018); Erdoğan et al. (2019); Erdoğan et al. (2020); Erdoğan, Yıldırım and Gedikli (2019); and Lemoine (2019) pointed out the interrelation between economic growth, technological innovation and increasing energy consumption which leads rebound effect. 
Moreover, the level of development of the countries may be also crucial in analyzing the contribution of transport sector to the carbon emissions. The findings of the researches considering the development level of the countries in order to find solutions to combat the increase in carbon emissions on a global scale may be helpful. In this context, the questions to be answered in order to determine the relationship between the level of development of countries and the magnitude of carbon emissions are listed below:

- The lower the economic growth, the less allocation of sources to be transferred to innovation. Does using low technologies in transport sector result in high carbon emissions?

-Does higher income per capita in developed countries aggravate carbon emissions due to increasing demand for energy-saving vehicles? Yet, drivers may be more comfortable to drive more if they believe that their vehicles consume less fuel and produce less pollutant.

\section{-How does demand to have car and demand to drive affect carbon emissions?}

-Indeed, the level of development difference among the countries in the Mediterranean region is significant. Does it make a difference in carbon emissions?

In this vein, the aim of this study is to investigate whether there is a difference between developed Mediterranean countries and developing Mediterranean countries regarding the impact of innovation on the transport sector and carbon emissions. Mediterranean basin has been an important and strategic region. However, macroeconomic performances of EuroMediterranean countries are far better than most of the Eastern and Southern Mediterranean countries. Therefore, there are great differences between their R\&D expenditures, economic growth rates, GDP per capita, and the level of innovation investments. Furthermore, their energy efficiency technologies, their means of the transport sector, as well as their environmental policies and level of environmental awareness, are not homogenous in sample countries. To provide a precise analysis, we divided the Mediterranean countries into two groups as developed Mediterranean countries and developing Mediterranean countries. Based on the available reliable data, Albania, Algeria, Bosnia and Herzegovina, Croatia, Egypt, Morocco, Tunisia, and Turkey are selected as the 8 developing countries; and Cyprus, France, Greece, Israel, Italy, Spain are selected as the 6 developed countries. Due to data constraints, the analysis period has been determined as 1997-2017 for the developing Mediterranean countries, and 2003-2017 for the developed Mediterranean countries. After determining the long-term relationship with the panel cointegration method, we obtained the long-term coefficients with FMOLS and DOLS methods. We applied Pedroni cointegration test. It allows for panel-specific cointegrating vectors and based on the stationarity test of error terms with panel and group tests statistics (v, rho, ADF and PP).

To the best of our knowledge, there is no other study that investigates the effects of innovation on the transport sector carbon emissions in the Mediterranean countries. Hence, the contribution of our paper to the related literature is analyzing the relationship between innovation and transport sector carbon emissions in the developed and developing Mediterranean countries. 
The remainder of the paper is organized as follows: The second part is the literature review. The third part introduces the model; the fourth part explains the data and methodology, the statistical properties of data, and stylized facts; and the last part presents the empirical results and policy implications.

\section{LITERATURE REVIEW}

The literature review of our study will be analyzed under two headlines: The first headline is the relationship between the transportation sector and $\mathrm{CO}_{2}$ emissions. And the second one is the relationship between innovation and $\mathrm{CO}_{2}$ emissions.

\section{Innovation and $\mathrm{CO}_{2}$ emissions}

Johnstone, Haščič and Popp (2010) examined the effects of environmental policies on technological innovation in the case of renewable energy on the 25 OECD countries using the panel data during the period 1978-2003. The researchers concluded that public policy had a crucial role in determining patent applications and the development of new renewable energy technologies. The authors pointed the public expenditures on R\&D as well as the Kyoto Protocol that encouraged the patent activities on wind and solar power as the significant effects on increasing innovation activities.

Feia, Rasiah, and Shen (2014) investigated the energy-growth nexus by taking the effects of clean energy, $\mathrm{CO}_{2}$ emissions, and technological innovation into account in Norway and New Zealand during the period 1971-2010. The authors indicated that there was a long-term equilibrium between clean energy, economic growth, and $\mathrm{CO}_{2}$ emissions. They also showed that while clean energy alleviates the $\mathrm{CO}_{2}$ emissions, it also brings extra cost on the economic growth of both countries. While technological innovation implies advancements in energy efficiency, New Zealand does not intend to apply technological innovation in clean energy production. Irandoust (2016) analyzed the relationship between renewable energy consumption, technological innovation, $\mathrm{CO}_{2}$ emissions, and economic growth in the Nordic countries (Denmark, Finland, Norway $\mathrm{CO}_{2}$, and Sweden). The empirical results indicated that there was a unidirectional causality running from technological innovation to renewable energy and from renewable energy to economic growth for all sample countries. The authors pointed out the importance of technological innovation on renewable energy and economic growth. In another study for China, Zhang et al. (2017) investigated the effect of environmental innovations during 2000-2013 using SGMM technique. They indicated that resource innovation, knowledge innovation as well as environmental innovation measures reduce $\mathrm{CO}_{2}$ emissions effectively in China. Samargandi (2017) reached similar findings for the case of Saudi Arabia. Mensah et al. (2018) investigated the effects of innovation on $\mathrm{CO}_{2}$ emission in 28 OECD countries over the period 1990-2014 using the STIRPAT model. The researchers concluded that innovation has a crucial role in the mitigation of $\mathrm{CO}_{2}$ emissions. They also pointed out that the higher the GDP per capita, the greater the rise in $\mathrm{CO}_{2}$ emissions. Kahouli (2018), examined the causality relationship between energy electricity consumption, $\mathrm{R} \& \mathrm{D}$ stocks, $\mathrm{CO}_{2}$ emissions, and economic growth in Mediterranean countries 
over the period 1990-2016. The empirical results indicated the existence of strong feedback effects between electricity, $\mathrm{R} \& \mathrm{D}$ stocks, $\mathrm{CO}_{2}$ emissions, and economic growth. It was also found that there was a one-way causality between R\&D stocks and economic growth, and a unidirectional causality between $\mathrm{R} \& \mathrm{D}$ and $\mathrm{CO}_{2}$ emissions.

Danish (2019) also found that the ICT mitigates the $\mathrm{CO}_{2}$ emissions in the 59 countries along Belt and Road spanning the period 1990-2016. Petrovic and Lobanov (2020) analyzed the impact of $\mathrm{R} \& \mathrm{D}$ expenditures on $\mathrm{CO}_{2}$ emissions in 16 OECD countries for the period between 1981 and 2014. Shahbaz et al. (2020) revealed parallel results in their study on the role of technological innovations in China. The authors found that technological innovations have a negative impact on $\mathrm{CO}_{2}$ emissions. Nguyen, Pham, and Tram (2020) confirm this finding. The authors investigated 13 selected G-20 countries over the period 2000-2014 and concluded that together with energy price, foreign direct investment, and trade openness, technology and spending on innovation have a mitigating effect over $\mathrm{CO}_{2}$ emissions. The authors found statistically significant relationships between $\mathrm{CO}_{2}$ emissions, innovation, and ICT. The authors found that $\mathrm{R} \& \mathrm{D}$ investment has negative effects on $\mathrm{CO}_{2}$ emissions in the long-term. They showed that a $1 \%$ growth of $\mathrm{R} \& \mathrm{D}$ investments mitigates $\mathrm{CO}_{2}$ emissions by $0.09 \%$ $0.15 \%$ on average. Wen et al. (2020) analyzed the spillover effects of technological innovation on $\mathrm{CO}_{2}$ emissions in 30 provinces of China spanning the period 2000-2015 in the construction sector. The authors indicated the key role of technological innovation in $\mathrm{CO}_{2}$ emission reduction in the construction industry.

Although most of the studies in the literature indicated the moderating effects of innovation on $\mathrm{CO}_{2}$ emissions, there are some studies that reached different results:

Álvarez-Herránz et al. (2017) employed a panel data set of 28 OECD countries to analyze the effects of improvements in energy research development on greenhouse gas emissions using ERD\&D model spanning the period 1990-2014. The empirical results indicated that energy innovation measures could not reach its whole impacts at once, instead, it needs more time to reach the targets and their full effect.

Amri, Bélaïd and Roubaud (2019) investigated the moderating role of technological innovation on the devastating effects of trade and energy consumption on environmental sustainability in Tunisia spanning the period 1971-2014 using ARDL approach. They found that there was no causality between technological innovation and $\mathrm{CO}_{2}$ emissions and there was a unidirectional impact of technological innovation on energy consumption both in short and long terms. Besides, technological innovation had indirectly significant by decreasing the impact of energy consumption on $\mathrm{CO}_{2}$ emissions.

Khattak (2020) analyzed the effects of innovation, renewable energy, and GDP per capita on $\mathrm{CO}_{2}$ emissions in BRICS countries over the period 1980-2016. The test results showed that technological innovation could not mitigate the $\mathrm{CO}_{2}$ emissions in China, India, Russia, and South Africa. It was found that there was bidirectional causality between innovation and $\mathrm{CO}_{2}$ emissions; innovation and GDP per capita; innovation and renewable energy consumption and between $\mathrm{CO}_{2}$ emissions and GDP per capita. 
Although most of the literature focuses on how innovation contributes to alleviating climate impact on the environment by examining the mitigating innovative technologies, Su and Moaniba (2017) tried to analyze the causality via a reverse approach. The authors analyzed the effects of climate changes on innovation technologies on a dataset of 70 countries. The authors concluded that increasing levels of $\mathrm{CO}_{2}$ emissions cause more innovations related to climate change. Therefore, the author suggested diverting public funds to innovative activities that contribute to combating climate change.

$\mathrm{Du}, \mathrm{Li}$ and Yan (2019) investigated the effects of green technology innovations on $\mathrm{CO}_{2}$ emissions in 71 countries for the period 1996-2012. Based on the empirical findings, it was indicated that green technology innovations do not have a significant impact on mitigating $\mathrm{CO}_{2}$ emissions in economies whose income level is below the threshold. On the contrary, the economies whose income level is above the threshold reduction effects became significant. The authors also found that $\mathrm{CO}_{2}$ emission per capita and per capita GDP is inverted U-shaped, and urbanization level and industrial structure.

Koçak and Şentürk Ulucak (2019) examined the effects of R\&D expenditures on $\mathrm{CO}_{2}$ emissions using the STIRPAT model for OECD countries during the period 2003-2015. The empirical results showed that, contrary to the expectations, there was a significant positive relationship between the $R \& D$ expenditures and $\mathrm{CO}_{2}$ emissions due to $\mathrm{R} \& \mathrm{D}$ improvements in energy efficiency and fossil fuel. The authors also found that the power and storage R\&D expenditures have a mitigating effect on $\mathrm{CO}_{2}$ emissions.

\section{Transportation and $\mathrm{CO}_{2}$ emissions}

Zhou, Chung, and Zhang (2013) examined the $\mathrm{CO}_{2}$ emissions performance of China's transport sector over the period 2003-2009 using undesirable-output-oriented DEA models. The empirical results indicated that the number of environmentally efficient regions decreased in the given period. The authors also found that the Eastern region of the country had the best results in adjusting $\mathrm{CO}_{2}$ emissions as transport infrastructure facilities are better in this region. Hence, they underlined the importance of the development of transport infrastructure technologies in the abatement of $\mathrm{CO}_{2}$ emissions.

Li et al. (2013) explored the effects of factors such as vehicle fuel intensity, working vehicle stock per freight transport operator, industrialization level, and economic growth on the $\mathrm{CO}_{2}$ emissions from road freight transportation in China over the period 1985-2007. The test results showed that while economic growth is the most important factor in increasing $\mathrm{CO}_{2}$ emissions, the ton-kilometer per value added of industry and the market concentration level significantly decrease $\mathrm{CO}_{2}$ emissions.

Guo et al. (2014) analyzed the contributions of population, energy intensity, energy structure, and economic activities to $\mathrm{CO}_{2}$ emission increments in the transport sector spanning the period 2005-2012 in different provinces and regions of China. The authors concluded that the Eastern region of China had the highest $\mathrm{CO}_{2}$ emissions and per capita $\mathrm{CO}_{2}$ emissions, but the 
lowest $\mathrm{CO}_{2}$ emissions intensity in its transport sector whereas the Western side had the highest $\mathrm{CO}_{2}$ emission intensity and the fastest emission increasing trend in its transport sector. They also pointed out that there has been a great increase in $\mathrm{CO}_{2}$ emissions in the transport sector in parallel to economic activities.

Fan and Lei (2016) explored the impact of transportation intensity, energy structure, energy intensity, the output value of per unit traffic turnover, population, and economic growth on $\mathrm{CO}_{2}$ emissions in the transportation sector over the period 1995-2012 using GFI model in Beijing-China. The authors found that economic growth, energy intensity, and size of the population are the primary reasons for transportation carbon emissions. They also found that transportation intensity and energy structure are the negative drivers of $\mathrm{CO}_{2}$ emissions in the transportation sector.

Wang and $\mathrm{He}$ (2017) investigated the $\mathrm{CO}_{2}$ marginal mitigation costs of the regional transportation sector, $\mathrm{CO}_{2}$ emissions efficiency, economic efficiency, and productivity in China from 2007 to 2012. The authors found that $\mathrm{CO}_{2}$ emissions efficiency and marginal mitigation cost of $\mathrm{CO}_{2}$ emissions are negatively correlated. Hence, improving $\mathrm{CO}_{2}$ emissions efficiency leads to a reduction in $\mathrm{CO}_{2}$ marginal mitigation costs.

Zhu and $\mathrm{Du}$ (2019) analyzed the driving factors of $\mathrm{CO}_{2}$ emissions of road transportation in Australia, Canada, China, India, Russia, and the USA by employing LMDI decomposition method covering the period of 1990-2016. The empirical results indicated that carbon emissions of road transportation had a dramatic increase since 1990 (84.43\%). Besides, both the economic output and the increasing population had positive effects on $\mathrm{CO}_{2}$ emissions of the road transportation sector.

$\mathrm{Du}$ et al. (2019) analyzed the relationship between the transportation sector and the Chinese economy from 2002 to 2012 . The authors searched the effects of all means of transportation, i.e. the rail, road, water, and air on the generation of $\mathrm{CO}_{2}$ emissions. The empirical findings indicated that the road sub-sector increased $\mathrm{CO}_{2}$ emissions whereas the rail sub-sector resulted in mitigation in $\mathrm{CO}_{2}$ emissions due to technological advances.

Khan et al. (2020) investigated the sectorial effects on $\mathrm{CO}_{2}$ emission in Pakistan over the period 1991-2017. The researcher revealed that while the agriculture and services sectors have a negative effect on $\mathrm{CO}_{2}$ emissions, the construction, manufacturing, and transportation sectors contribute to the $\mathrm{CO}_{2}$ emissions. They also pointed out the importance of technological innovations for the $\mathrm{CO}_{2}$ emissions reduction strategies.

Georgatzi, Stamboulis, and Vetsikas (2020) examined the determinants of $\mathrm{CO}_{2}$ emissions due to the transport sector for 12 European countries during the period 1994-2014 using panel data analysis and the Granger causality test. Based on the test results, it was concluded that infrastructure investments by the transport sector do not have a significant effect on $\mathrm{CO}_{2}$ emissions; and also there was a bidirectional relationship between environmental policy stringency and $\mathrm{CO}_{2}$ emissions. 
Although in most of the studies researchers found similar results that point to the positive relationship between the transport sector and $\mathrm{CO}_{2}$ emissions, some papers indicated that the results may vary. In their study on the impact of public transportation on $\mathrm{CO}_{2}$ emissions for Chinese provinces, Jiang, Zhou and Liu (2018) concluded that although the results were heterogeneous, the findings support inverted U-shaped nexus between public transportation and $\mathrm{CO}_{2}$ emissions for provinces whose $\mathrm{CO}_{2}$ emission levels are different. Hence, if the public transportation level exceeds a threshold value, the relationship between the two variables may turn from positive to negative.

\section{DATA}

This study examines the relationship between innovation and transportation sector carbon emissions in developed and developing Mediterranean countries. The development levels of counties are considered as one of the main antecedents of innovation capability and transportation habits. In this context, in this study Mediterranean countries are divided into two groups as developed and developing Mediterranean countries. On the basis of real GDP, IMF (2019) classified eight countries (Cyprus, France, Greece, Israel, Italy, Malta, Slovenia, Spain) as developed and ten countries (Albania, Algeria, Bosnia, and Herzegovina, Croatia, Egypt, Lebanon, Libya, Morocco, Tunisia, Turkey) as emerging or developing Mediterranean countries. According to this classification of IMF and depending on the availability of data, the relationship between innovation and carbon emissions from the transport sector in eight developing countries (Albania, Algeria, Bosnia and Herzegovina, Croatia, Egypt, Morocco, Tunisia, and Turkey) will be analyzed with annual data between 1997 and 2017. Because of the data constraints, for six developed countries (Cyprus, France, Greece, Israel, Italy, Spain) innovation-carbon emission nexus through transport sector will be investigated over the period 2003-2017.

The estimation equations are as follows.

tco $_{i t}=\beta_{0}+\beta_{1}$ patent $_{i t}+\beta_{2} \operatorname{lngdppc}_{i t}+\beta_{3} X_{i t}+\varepsilon_{i t}$

Equation (1)

tco $2_{i t}=\beta_{4}+\beta_{5}$ patent $_{i t}+\beta_{6}$ lngdppc $_{i t}+\beta_{7} \operatorname{lngdpp} c_{i t}^{2}+\beta_{8} X_{i t}+\varepsilon_{i t}$ Equation (2) $t c o 2_{i t}=\alpha_{0}+\alpha_{1} t_{i t}+\alpha_{2} \operatorname{lngdpp} c_{i t}+\alpha_{3} X_{i t}+\varepsilon_{i t}$

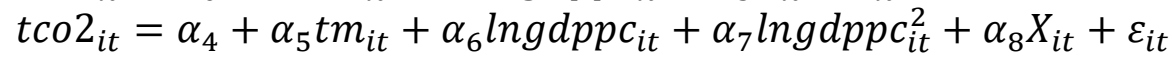

The abbreviations in the equations define the following concepts: tco $2_{i t}$ : $\mathrm{CO} 2$ emissions from the transport sector patentit: Number of patent applications $t m_{i t}$ : Number of trademark applications $\operatorname{lngdppc}_{i t}$ : Per capita income $\operatorname{lngdppcit}{ }^{2}$ : The square of per capita income $X_{i t}$ : Control variables. 
In the equations, the number of patents and number of trademarks are considered as indicators of innovation capability, whilst trade (trade openness), FD (financial development), urban (the number of people living in urban areas) and energy (energy consumption) are the control variables.

In order to test the validity of the Kuznets hypothesis, Equation 2 and equation 4 are created as quadratic equations.

$\mathrm{CO}_{2}$ emissions from transport ( $\mathrm{Mt} \mathrm{CO}_{2} / \mathrm{yr}$ ) include sources from fossil fuel use (combustion, flaring), industrial processes (cement, steel, chemicals, and urea), and product use (Muntean et.al. (2018)). Patent applications are worldwide patent applications filed through the Patent Cooperation Treaty procedure or with a national patent office for exclusive rights for an invention. A patent provides protection for the invention (a product or process that provides a new way of doing something or offers a new technical solution to a problem) to the owner of the patent. TM (Trademark Applications) is the number of applications to register a trademark with a national or regional (registered to Intellectual Property (IP) office). GDP per capita is gross domestic product divided by midyear population. GDP is the sum of gross value added by all resident producers in the economy plus any product taxes and minus any subsidies. Data are in current U.S. dollars. Trade (Trade openness) is the value of exports of goods and services + the value of imports of goods and services / GDP (\%). FD: Financial development (domestic credit to the private sector by banks (\% of GDP)) refers to financial resources provided to the private sector by financial corporations. Urban (the World Bank population estimates) refers to the number of people living in urban areas. Energy (quad Btu) refers to the use of primary energy consumption. Energy use data were obtained from the U.S. Energy Information Administration, carbon emission from transport data were obtained from the Muntean et al. (2018) - (European Union Report- Fossil $\mathrm{CO}_{2}$ emissions of all world countries) reports and other data were obtained from the World Bank. In the study, all data except energy were taken as the natural logarithm. Descriptive Statistics of the data are shown in Table 1.

Table 1: Descriptive Statistics

\begin{tabular}{|c|c|c|c|c|c|c|c|c|}
\hline \multicolumn{9}{|c|}{ Variables } \\
\hline & TCO2 & GDPPC & EC & TM & PAT & FD & TRADE & URBAN \\
\hline & \multicolumn{8}{|c|}{ Developed Countries } \\
\hline Min. & 1.7 & 18116.5 & 0.1 & 1569.0 & 3.0 & 57.17 & 45.6 & 681117.0 \\
\hline Max. & 133.1 & 45334.1 & 11.5 & 94917.0 & 17290.0 & 253.2 & 133.0 & 53612472.0 \\
\hline St. Err. & 51.0 & 6723.7 & 4.0 & 30308.6 & 5778.6 & 52.0 & 22.5 & 19228178.0 \\
\hline \multirow[t]{2}{*}{ Average } & 62.1 & 30512.1 & 4.5 & 33640.9 & 6192.6 & 115.0 & 68.4 & 23898068.4 \\
\hline & \multicolumn{8}{|c|}{ Developing Countries } \\
\hline Min. & 1.3 & 1033.2 & 0.1 & 2224.0 & 4.0 & 4.9 & 30.2 & 1279853.0 \\
\hline Max. & 85.9 & 16357.2 & 6.4 & 119304.0 & 8555.0 & 95.5 & 121.8 & 60537696.0 \\
\hline St. Err. & 19.0 & 3600.9 & 1.5 & 25449.5 & 1309.2 & 22.6 & 19.4 & 16860375.1 \\
\hline Average & 18.4 & 4800.9 & 1.4 & 15436.7 & 1010.2 & 45.1 & 72.1 & 17261533.7 \\
\hline
\end{tabular}

According to descriptive statistics in Table 1, the yearly average of $\mathrm{CO}_{2}$ emissions from the transport sector in developed countries is $62.1(\mathrm{Mt} \mathrm{CO} 2)$, whereas it is $18.4\left(\mathrm{Mt} \mathrm{CO}_{2}\right)$ in developing countries. This shows that $\mathrm{CO}_{2}$ emissions from the transport sector in developed 
countries are 3.5 times greater than developing countries. While average GDP per capita in the developed countries is $\$ 30,500$, it is $\$ 4800$ in the developing countries. The energy consumption of developed countries is approximately three times that of developing countries. Although there is not a significant difference between the international trade performances of developed and developing countries, the developed Mediterranean countries showed a remarkable performance in the financial development and innovation. Finally, the average urban population is 23.9 million for developed countries, whereas it is 17.2 million for developing countries.

\section{Methodology \& Empirical Results}

The purpose of this study is to investigate the effect of innovation on carbon emission from the transport sector in Mediterranean region countries. The stationarity of the series is important in choosing the preferred estimation method. Therefore, the first step of the analysis is to investigate the stationarity of the series. Another important factor affecting the estimation results in panel data analysis is cross-section dependency. O'Connell (1998) showed that cross-section dependency increases the possibility of rejecting the null- hypothesis. Panel unit root tests can be divided into two (1) First-generation unit root tests assuming cross-sectional independence of series and (2) Second generation unit root tests assuming cross-sectional dependence of series. In order to choose the appropriate estimation method, it is necessary to investigate the cross-sectional dependency of the series.

Pesaran (2004)'s CD test and Pesaran et al. (2008)'s LMadj (Bias-Adjusted Cross Sectionally Dependence Lagrange Multiplier) test was used to test the presence of cross-sectional dependence.

CD test statistics are calculated as follows.

$C D=\sqrt{\frac{2 T}{N(N-1)}\left(\sum_{i=1}^{N-1} \sum_{j=i+1}^{N} \hat{\rho}_{i j}\right)} \Rightarrow N(0,1)$

LMadj test statistics are calculated as follows.

$L M a d j=\sqrt{\frac{2}{N(N-1)}} \sum_{i=1}^{N-1} \sum_{j=i+1}^{N} T \hat{\rho}_{i j} \frac{(T-k) \widehat{\rho}_{i j}^{2}-\mu_{T i j}}{\sqrt{v_{T i j}^{2}}}$

Hypotheses of CD test;

$\mathrm{H} 0$ : no cross-sectional dependence

$\mathrm{H}_{1}$ : has the cross-sectional dependence

Table 2 shows the results of the cross-sectional dependency of the series.

Table 2: Cross-Sectional Dependence Tests

\begin{tabular}{|c|c|c|c|c|c|c|c|c|c|}
\hline & \multirow{6}{*}{$\frac{0}{0}$} & \multirow{2}{*}{$\begin{array}{l}\text { CD } \\
\text { Stat. }\end{array}$} & \multicolumn{2}{|c|}{ LMadj } & \multirow[b]{2}{*}{ Prob. } & \multirow{2}{*}{$\begin{array}{l}\text { CD } \\
\text { Stat. }\end{array}$} & \multirow[b]{2}{*}{ Prob. } & LMadj & \multirow[b]{2}{*}{ Prob. } \\
\hline Var & & & Prob. & Stat. & & & & Stat. & \\
\hline $\mathrm{TCO} 2$ & & -2.485 & 0.006 & 3.647 & 0.000 בصٌ & -1.656 & 0.049 & 0.931 & 176 \\
\hline $\mathrm{EC}$ & & -1.886 & 0.030 & 3.206 & 0.001 을 & -1.444 & 0.074 & 1.497 & 0.067 \\
\hline GDPI & & -1.163 & 0.122 & 4.066 & 0.000 ह & 1.044 & 0.148 & 3.142 & 0.001 \\
\hline PAT & & -2.364 & 0.009 & 12.741 & U صّم 0.000 & -1.636 & 0.051 & 1.243 & 0.107 \\
\hline
\end{tabular}




\begin{tabular}{|c|c|c|c|c|c|c|c|c|}
\hline TM & -1.425 & 0.077 & -0.124 & 0.549 & -1.367 & 0.086 & 0.629 & 0.265 \\
\hline TRADE & -2.138 & 0.016 & 0.294 & 0.384 & -1.834 & 0.033 & 1.823 & 0.034 \\
\hline URBAN & -1.304 & 0.096 & 27.471 & 0.000 & -1.026 & 0.152 & 1.354 & 0.088 \\
\hline FD & -2.092 & 0.018 & 0.550 & 0.291 & -0.630 & 0.264 & 5.511 & 0.000 \\
\hline
\end{tabular}

540

541

542

543

544

545

546

547

548

549

550

551

552

553

554

555

556

557

558

559

560

561

562

563

564

565

566

567

568

569

570

571

572

573

574

575

576

577

578

579

580

581

582

583

584

585

As shown in Table 2, according to the CD test results, the null- hypothesis is rejected at the $10 \%$ significance level. The basic hypothesis suggests that there is no cross-sectional dependency for all variables except the GDPPC series. Hence, it is decided that the crosssectional dependency problem exists. On the other hands, for the GDPPC series, it is seen that the basic hypothesis cannot be strongly rejected. On the other hand, according to the LMajd test result for the GDPPC series, the basic hypothesis suggesting that there is no crosssectional dependency is rejected and it is decided that the cross-sectional dependency problem exists. According to the results of LMajd test, it is decided that cross-sectional dependency problem exists for all series except for TM, TRADE and FD series.

According to CD test results at $10 \%$ significance level for developed countries, it is decided that cross-section dependency problem exists for all variables except GDPPC, URBAN and FD series. For these three variables, LMajd test statistics show that the cross-sectional dependency problem exists. According to the LMajd test result, it is decided that crosssectional dependency problem exists for all series except TCO2, PAT and TM series. However, the basic hypothesis cannot be strongly rejected within these series, the test statistics almost exceed the $10 \%$ level. As a result, it was decided that cross section dependency problem exists for all series in the analysis.

\section{PANIC TEST}

In our study, The PANIC (Panel Analysis of Non-stationarity in Idiosyncratic and Common Component) test proposed by Bai and $\mathrm{Ng}$ (2004) will be used. In this method, if the mean values added as explanatory variables are not stationary, regression analysis may be spurious regression. In this case, normal distribution will not be used. Also, in the CA method, the common factors and idiosyncratic term are assumed to be equally stationary. However, since the first difference of the variable is used in the PCA method, the problem of spurious regression disappears. Besides, since stationarity for the common factors and idiosyncratic term is considered separately, it is not necessary for them to be stationary at the same level.

The cross-section dependency problem can cause the estimation results to be biased for unit root analysis. While first-generation panel unit root tests assume cross-section independence, second generation panel unit root tests take cross-sectional dependency into account (see Bai and Ng (2004), Moon and Perron (2004), Pesaran (2007), and Chang (2002)). Second generation unit root tests handle common factors with CA (Cross-Average) or PCA (Principal Component) methods. In CA method, average values of cross-section units are added to the unit root estimation equation. However, if the mean values added as explanatory variables are not stationary in this method, regression analysis may be spurious regression. In this case, normal distribution cannot be used. Another issue is that in the CA method it is assumed that the common factors and idiosyncratic term are equally stationary. However, since the first difference of the variable is used in the PCA method, the problem of spurious regression has been resolved. In addition, since stationarity for the common factors and the idiosyncratic term is considered separately, it is not necessary to be stationary at the same level. 
The PANIC (Panel Analysis of Non-stationarity in Idiosyncratic and Common Component) test proposed by Bai and $\mathrm{Ng}$ (2004) allows the analysis of not only the observed variables but also the common factors. In the PANIC method, unobserved dynamic common factors are investigated by the principal components method. In this methodology it is proposed decomposing $\mathrm{Y}_{\text {it }}$ into three components; Deterministic component $\left(\mathrm{D}_{\mathrm{it}}\right)$, common factors $\left(\mathrm{F}_{\mathrm{t}}\right)$, and idiosyncratic component ( $\mathrm{e}_{\mathrm{it}}$ ). In other words, it is assumed that $\mathrm{Y}_{\text {it }}$ consists of these three components. The $\mathrm{Y}_{\text {it }}$ can be seen in Equation (7).

$Y_{i t}=D_{i t, p}+\lambda_{i}^{\prime} F t+e_{i t}$

In equation (7) $D_{\text {it }}$ represents polynomial trend function, $F_{t}: F t=[F 1 t, F 2 t, \ldots, F r t] '$ is a $r \times 1$ vector of common factors and $\lambda \mathbf{i}=[\lambda 1, \lambda 2, \ldots, \lambda \mathbf{r}]^{\prime}$ is a vector of factor loadings.

By predicting Equation (7), not only the stationarity of common factors but also the stationarity of the idiosyncratic components can be investigated. If at least one of the common factors or idiosyncratic component is nonstationary, it is decided that the variable is nonstationary. On the other hand, if both components are stationary, the variable is considered as stationary. In the PANIC test, the null hypothesis represents the unit root.

In other unit root test methods, tests may tend to reject the null-hypothesis, especially when one of the components is strongly I (0) and the other is I (1). This problem is eliminated since the components are handled separately in the PANIC test. In addition, since the components are separated in the PANIC test, the degree of cross-section dependency of idiosyncratic components decreases. Finally, since more cross-sectional information can be used in the PANIC test, the estimation results are more reliable.

PANIC test statistics are shown in Equation (8), Equation (9), Equation (10) and Equation (11).

For $\mathrm{p}=0$ (Intercept Model)

$\mathrm{P}_{a, p=0}=\frac{\sqrt{N T}\left(\widehat{\rho}_{0}^{+}-1\right)}{\sqrt{2 \widehat{\phi}_{\varepsilon}^{4} \widehat{\omega}_{\varepsilon}^{4}}}$ and $\mathrm{P}_{b, p=0}=\frac{\sqrt{N T}\left(\hat{\rho}_{0}^{+}-1\right)}{\sqrt{\widehat{\phi}_{\varepsilon}^{4} /\left[\widehat{\omega}_{3} N^{-1} T^{-2} \sum_{i=1}^{N}\left(\hat{e}_{i,-1}^{0}\right)^{\prime} \hat{e}_{i,-1}^{0}\right]}}$

$\operatorname{PMSB}_{p=0}=\frac{\sqrt{N}\left(N^{-1} T^{-2} \sum_{i=1}^{N}\left(\hat{e}_{i,-1}^{0}\right)^{\prime} \hat{e}_{i,-1}^{0}-\widehat{\omega}_{\varepsilon}^{2} / 2\right)}{\sqrt{\widehat{\phi}_{\varepsilon}^{4} / 3}}$

For $\mathrm{p}=1$ (Intercept $\&$ Trend Model)

$\mathrm{P}_{a, p=1}=\frac{\sqrt{N T}\left(\widehat{\rho}_{1}^{+}-1\right)}{\sqrt{36 \widehat{\sigma}_{\varepsilon}^{4} \widehat{\phi}_{\varepsilon}^{4} / 5 \widehat{\omega}_{\varepsilon}^{8}}}$ and $\mathrm{P}_{b, p=1}=\frac{\sqrt{N T}\left(\widehat{\rho}_{1}^{+}-1\right)}{\sqrt{6 \widehat{\sigma}_{\varepsilon}^{4} \widehat{\phi}_{\varepsilon}^{4} /\left[5 \widehat{\omega}_{\varepsilon}^{6} N^{-1} T^{-2} \sum_{i=1}^{N}\left(\hat{e}_{i,-1}^{0}\right)^{\prime} e_{i,-1}^{0}\right]}}$

$\operatorname{PMSB}_{p=1}=\frac{\sqrt{N}\left(N^{-1} T^{-2} \sum_{i=1}^{N}\left(\hat{e}_{i,-1}^{0}\right)^{\prime} \hat{e}_{i,-1}^{0}-\widehat{\omega}_{\varepsilon}^{2} / 6\right)}{\sqrt{\widehat{\phi}_{\varepsilon}^{4} / 45}}$

PANIC test statistics ( $\mathrm{Pa}$ and $\mathrm{Pb}$ ) are included in Equation (8) and Equation (10). PMSB (Panel Modified Sargan - Bhargava) shows the corrected Sargan Bhargava test statistics in the case of autocorrelation in Equation (9) and Equation (11). 
Unit root results are shown in Annex 1. Developing country results are included in the first part of the table. According to the intercept model results, the null- hypothesis cannot be rejected at the 5\% significance level for TCO2, TM, TRADE, and URBAN series, and it is decided that these series are stationary. The other series are not stationary. According to the results of intercept and trend models, the null hypothesis cannot be rejected for all series except EC series and it is decided that the series are nonstationary. For the EC series, the nullhypothesis for Pa statistics is rejected. However, Pb and PMSB statistics show that the series is nonstationary. As a result, considering that there is a trend effect in series in general, it is decided that all series are nonstationary at the 5\% significance level based on the results of the intercept and trend model.

The second part of the table includes the results of developed countries. The null- hypothesis cannot be rejected according to the Pb statistics for the GDPPC, TRADE, and URBAN series for the intercept model. However, the null-hypothesis is rejected for Pa and PMSB test statistics. According to $\mathrm{Pa}$ and $\mathrm{Pb}$ statistics for TCO2 series, the null- hypothesis cannot be rejected, but the null-hypothesis is rejected for the PMSB test statistics. The results of the intercept and trend model indicated that the null- hypothesis cannot be rejected for all series except the PAT series and it is decided that the series are nonstationary. For the PAT series, the null- hypothesis cannot be strongly rejected. In addition, $\mathrm{Pb}$ and PMSB statistics show that the series is nonstationary. As a result, since we consider that there is trend effect in series as a general similar to the developing countries, it is decided that all series are nonstationary at the $5 \%$ significance level based on the results of fixed and trended model.

After investigating the degree of integration of the series, it is necessary to determine whether the estimation equations provide the assumption of cross-section independence and homogeneity in order to select the appropriate co-integration method and estimators. As explained before, for cross-section dependence, Pesaran (2004) CD test and Pesaran et.al. (2008) LMadj (Bias-Adjusted Cross Sectionally Dependence Lagrange Multiplier) are used. In order to investigate the homogeneity assumption, Pesaran and Yamagata (2008) tests that are widely used in the literature are preferred.

Pesaran and Yamagata (2008) proposed the delta $(\Delta)$ test by developing the Swamy (1970) test to investigate homogeneity (Pesaran, Yamagata, 2008: 54-55). Test statistics and hypotheses of the Delta Test are as follows:

$\widehat{\Delta}=\sqrt{N}\left(\frac{N^{-1} \hat{S}-k}{\sqrt{2 k}}\right)$ for bigger sample

$\tilde{\Delta}_{a d j}=\sqrt{N}\left(\frac{N^{-1} \tilde{S}-k}{\sqrt{2 k}}\right)$ for smaller sample

$\mathrm{H} 0: \beta i=\beta$, slope coefficients are homogeneous

$\mathrm{H} 1: \beta \neq \beta j$, slope coefficients are not homogeneous

Table 3 shows the test results of the equations considered within the scope of the analysis for homogeneity and cross-section dependency.

Table 3: Homogeneity \& Cross-Sectional Dependency Tests for Equations

Developed Countries

\begin{tabular}{lllllllll} 
& \multicolumn{1}{c}{ Eq.1 } & & Eq.2 & & Eq.3 & & Eq.4 & \\
\hline Homogeneity & Stat & Prob & Stat & Prob & Stat & Prob & Stat & Prob \\
\hline
\end{tabular}




\begin{tabular}{|c|c|c|c|c|c|c|c|c|}
\hline$\widehat{\Delta}$ & 3.652 & 0.000 & 2.774 & 0.003 & 3.798 & 0.000 & 2.886 & 0.002 \\
\hline$\tilde{\Delta}_{a d j}$ & 5.164 & 0.000 & 4.195 & 0.000 & 5.372 & 0.000 & 4.363 & 0.000 \\
\hline CSD & Stat & Prob & Stat & Prob & Stat & Prob & Stat & Prob \\
\hline $\mathrm{CD}$ & -0.078 & 0.469 & 0.289 & 0.386 & 0.218 & 0.414 & 0.080 & 0.468 \\
\hline \multirow[t]{3}{*}{ LMadj } & 0.911 & 0.181 & 0.179 & 0.429 & 0.400 & 0.344 & 0.065 & 0.474 \\
\hline & \multicolumn{8}{|c|}{ Developing Countries } \\
\hline & Eq.1 & & Eq. 2 & & Eq. 3 & & Eq.4 & \\
\hline Homogeneity & Stat & Prob & Stat & Prob & Stat & Prob & Stat & Prob \\
\hline$\widehat{\Delta}$ & 4.243 & 0.000 & 3.382 & 0.000 & 4.420 & 0.000 & 3.709 & 0.000 \\
\hline$\tilde{\Delta}_{a d j}$ & 5.478 & 0.000 & 4.561 & 0.000 & 5.706 & 0.000 & 5.002 & 0.000 \\
\hline CSD & Stat & Prob & Stat & Prob & Stat & Prob & Stat & Prob \\
\hline $\mathrm{CD}$ & -1.102 & 0.135 & -0.562 & 0.287 & -0.718 & 0.236 & -0.395 & 0.347 \\
\hline LMadj & -0.992 & 0.839 & 0.464 & 0.321 & -1.463 & 0.928 & -1.206 & 0.886 \\
\hline
\end{tabular}

676

677

678

679

680

681

682

683

684

685

686

687

688

689

690

691

692

693

694

695

696

697

698

699

700

701

702

703

704

705

706

707

708

709

710

According to the results in Table 3, the null hypothesis that the slope coefficient for the homogeneity test results is homogeneous is rejected and it is decided that all estimation equations are heterogeneous. On the other hand, according to both CD test (Pesaran,2004) and LMadj test (Pesaran et al.,2008), the basic hypothesis that suggests that there is no crosssectional dependency cannot be rejected for all equations and it is decided that the problem of cross-sectional dependency does not exist in the equations. Therefore, it is necessary to use heterogeneous models in data analysis. Also, taking the cross-sectional dependency into consideration is important. Nevertheless, since there is not cross-sectional-dependency for estimated equations in our samples, Pedroni and Durbin Hausman Panel Co-integration tests are preferred to investigate the co-integration relations between the series.

\section{Pedroni Panel Co-integration Test}

Pedroni cointegration test which allows for panel-specific cointegrating vectors, is based on the stationarity test of error terms with panel and group tests statistics (v, rho, ADF and PP). Pedroni test also allows individual slope coefficients and trend coefficients between crosssections. It developed seven test statistics consisting of within groups and between groups tests (within groups tests assume that the AR parameter is the same and the between groups tests assume that AR parameter vary). These test statistics consist of 4 within dimension (panel cointegration statistics) and 3 between dimension (group-mean statistics) tests. In the Pedroni cointegration test, the basic hypothesis suggests that there is no cointegration relationship is tested. Alternative hypothesis states that at least one unit is cointegrated. Group-mean statistics also provides additional information on heterogeneity between units. The seven predicted test statistics for cointegration analysis are shown below.

1) Panel v-Statistic: $T^{2} N^{3 / 2} Z_{\hat{v} N, T} \equiv T^{2} N^{3 / 2}\left(\sum_{i=1}^{N} \sum_{t=1}^{T} \hat{L}_{11 i}^{-2} \hat{e}_{i, t-1}^{2}\right)^{-1}$

2) Panel $\rho$-Statistic: $T \sqrt{N} Z_{\hat{p} N, T-1} \equiv T \sqrt{N}\left(\sum_{i=1}^{N} \sum_{t=1}^{T} \hat{L}_{11 i}^{-2} \hat{e}_{i, t-1}^{2}\right)^{-1} \sum_{i=1}^{N} \sum_{t=1}^{T} \hat{L}_{11 i}^{-2}\left(\hat{e}_{i, t-1}^{2} \Delta \hat{e}_{i, t}-\hat{\lambda}_{i}\right)$

3) Panel t-Statistic: $\quad Z_{t N, T} \equiv\left(\tilde{\sigma}^{2} \sum_{i=1}^{N} \sum_{t=1}^{T} \hat{L}_{11 i}^{-2} \hat{e}_{i, t-1}^{2}\right)^{-1 / 2} \sum_{i=1}^{N} \sum_{t=1}^{T} \hat{L}_{11 i}^{-2}\left(\hat{e}_{i, t-1}^{2} \Delta \hat{e}_{i, t}-\hat{\lambda}_{i}\right) \quad$ (nonparametric) (16)

4) Panel t-Statistic: $Z_{t N, T}^{*} \equiv\left(s_{N, T}^{* 2} \sum_{i=1}^{N} \sum_{t=1}^{T} \hat{L}_{11 i}^{-2} \hat{e}_{i, t-1}^{* 2}\right)^{-1 / 2} \sum_{i=1}^{N} \sum_{t=1}^{T} \hat{L}_{11 i}^{-2}\left(\hat{e}_{i, t-1}^{* 2} \Delta \hat{e}_{i, t}^{*}\right)$ (parametric)

5) Group $\rho$-Statistic: $T N^{-1 / 2} \tilde{Z}_{\hat{\rho} N, T-1} \equiv T N^{-1 / 2} \sum_{i=1}^{N}\left(\sum_{t=1}^{T} \hat{e}_{i, t-1}^{2}\right)^{-1} \sum_{t=1}^{T}\left(\hat{e}_{i, t-1} \Delta \hat{e}_{i, t}-\hat{\lambda}_{i}\right)$

6) Group t-Statistic: $\quad N^{-1 / 2} \tilde{Z}_{t N, T} \equiv N^{-1 / 2} \sum_{i=1}^{N}\left(\hat{\sigma}_{i}^{2} \sum_{t=1}^{T} \hat{e}_{i, t-1}^{2}\right)^{-1 / 2} \sum_{t=1}^{T}\left(\hat{e}_{i, t-1} \Delta \hat{e}_{i, t}-\hat{\lambda}_{i}\right)$ (nonparametric) (19) 
7) Group t-Statistic: $N^{-1 / 2} \tilde{Z}_{t N, T}^{*} \equiv N^{-1 / 2} \sum_{i=1}^{N}\left(\sum_{t=1}^{T} \hat{S}_{i}^{* 2} \hat{e}_{i, t-1}^{2}\right)^{-1 / 2} \sum_{t=1}^{T} \hat{e}_{i, t-1}^{* 2} \Delta \hat{e}_{i, t}^{*}$ (parametric) (20)

Pedroni (2004), panel-t and group-t statistics are obtained from the regressions shown below:

$\hat{e}_{i, t}=\hat{\gamma}_{i} \hat{e}_{i, t-1}+\hat{\mu}_{i, t}$,

$\hat{e}_{i, t}=\hat{\gamma}_{i} \hat{e}_{i, t-1}+\sum_{k=1}^{K_{i}} \hat{\gamma}_{i, k} \Delta \hat{e}_{i, t-k}+\hat{\mu}_{i, t}^{*}$

Panel - $\rho$ and panel - $\mathrm{t}$ statistics are estimated by the long-term variance of $\eta_{i t}$ by the following regression:

$\Delta Y_{i t}=\alpha_{i}+\delta_{i} t+\beta_{i} \Delta X_{i t}+\eta_{i t}$

Pedroni panel co-integration test results are shown in Table 4.

Table 4: Pedroni Panel Co-integration Test

Developing Countries

\begin{tabular}{|c|c|c|c|c|c|c|c|c|}
\hline \multirow{2}{*}{$\begin{array}{l}\text { Test } \\
\text { Stat }\end{array}$} & \multicolumn{2}{|c|}{ Equation(1) } & \multicolumn{2}{|c|}{ Equation(2) } & \multicolumn{2}{|c|}{ Equation(3) } & \multicolumn{2}{|c|}{ Equation(4) } \\
\hline & Panel Stat. & $\begin{array}{c}\text { Group } \\
\text { Stat. }\end{array}$ & Panel Stat. & Group Stat. & Panel Stat. & $\begin{array}{c}\text { Group } \\
\text { Stat. }\end{array}$ & Panel Stat. & Group Stat. \\
\hline $\mathbf{V}$ & -1.844 & & -2.253 & & -2.053 & & -2.084 & \\
\hline rho & 2.94 & 4.073 & 3.033 & 4.131 & 3.504 & 4.324 & 3.623 & 4.612 \\
\hline $\mathbf{T}$ & -4.137 & -4.761 & -8.426 & -8.836 & -2.816 & -2.564 & -4.957 & -4.931 \\
\hline \multirow[t]{4}{*}{ adf } & 3.324 & 4.792 & 7.58 & 9.732 & -1.774 & 4.415 & 0.1782 & 5.005 \\
\hline & \multicolumn{8}{|c|}{ Developed Countries } \\
\hline & \multicolumn{2}{|c|}{ Equation(1) } & \multicolumn{2}{|c|}{ Equation(2) } & \multicolumn{2}{|c|}{ Equation(3) } & \multicolumn{2}{|c|}{ Equation(4) } \\
\hline & Panel Stat. & $\begin{array}{l}\text { Group } \\
\text { Stat. }\end{array}$ & Panel Stat. & Group Stat. & Panel Stat. & $\begin{array}{l}\text { Group } \\
\text { Stat. }\end{array}$ & Panel Stat. & Group Stat. \\
\hline $\mathbf{V}$ & -2.682 & & -3.173 & & -1.992 & & -2.18 & \\
\hline rho & 2.844 & 3.826 & 3.128 & 4.028 & 3.007 & 3.908 & 3.483 & 4.406 \\
\hline $\mathbf{T}$ & -9.18 & -10.08 & -11.92 & -12.31 & -6.686 & -8.862 & -6.631 & -9.893 \\
\hline adf & 0.3733 & 0.766 & 0.4446 & -1.422 & 1.401 & 2.633 & 2.754 & 2.639 \\
\hline
\end{tabular}

Note: Using the intercept model, the maximum delay was determined as 4 . The appropriate delay length is determined according to the AIC information criteria.

According to Table 4, the first part illustrates the test results for developing countries for both equations (2-4) with trademark variables and equations (1-3) with the patent variable. In the first part, according to all test statistics, the null hypothesis suggesting that there is no cointegration relationship between the series is rejected and it is decided that a co-integration relationship exists. On the other hand, according to the results regarding the developed countries in the second part, the null- hypothesis is rejected according to the other test statistics except for the adf test statistics for Equation (1), Equation (2), and Equation (3) and it is decided that a co-integration relationship exists. As an alternative to the Pedroni test, the Durbin-Hausman test was preferred since it presents panel and group statistics separately.

\section{Durbin-Hausman Panel Co-integration Test}

The Durbin-Hausman test, developed by Westerlund (2008), takes the cross-sectional dependency into account and presents both panel and group statistics. This test is effective, if the dependent variable is I (1), it is also effective when some of the independent variables are 
I (0) (Westerlund, 2008). Group statistics are based on the assumption of the heterogeneous panel (the autoregressive parameter is different for each section in the panel), and the Panel Statistics is based on the assumption of the homogeneous panel (the autoregressive parameter is the same for each section in the panel).

Test statistics and hypotheses are as follows.

$D H_{\text {Group }}=\sum_{i=1}^{N} \hat{S}_{i}\left(\widetilde{\emptyset}_{i}-\widehat{\emptyset}_{i}\right)^{2} \sum_{t=2}^{T} \hat{e}_{i t-1}^{2}$

$D H_{\text {Panel }}=\hat{S}_{i}\left(\widetilde{\emptyset}_{i}-\widehat{\emptyset}_{i}\right)^{2} \sum_{i=1}^{N} \sum_{t=2}^{T} \hat{e}_{i t-1}^{2}$

H0: There is no co-integration for all units.

H1: There is co-integration for some units.

Table 5 shows the Durbin-Hausman panel co-integration test results.

Table 5: Durbin-Hausman Panel Co-integration Test Test Statistics

Developing Countries

\begin{tabular}{lllll}
\multicolumn{1}{c}{ Test Statistics } & Equation (1) & Equation (2) & Equation (3) & Equation (4) \\
DH (Group Test Statistic) & -1.554 & -1.752 & -1.537 & -1.966 \\
DH (Panel Test Statistic) & 0.248 & -0.982 & 0.241 & -1.399 \\
& & \multicolumn{2}{c}{ Developed Countries } \\
& Equation (1) & Equation (2) & Equation (3) & Equation (4) \\
DH (Group Test Statistic) & -2.258 & 1.687 & -2.186 & 2.81 \\
DH (Panel Test Statistic) & -1.811 & 4.464 & -1.551 & 9.541
\end{tabular}

Note: The tests are based on an intercept and the Newey and West (1994) procedure for selecting the bandwidth order. Max factors are selected as 7.

The test results presented in Table 4 indicate that group statistics and panel statistics are given separately. For group statistics, the null- hypothesis is rejected at the $10 \%$ significance level for the equations involving both the trademark variable and patent variable and it is decided that there is a long-term relationship between the series. On the other hand, the results of the panel statistics are more complex. Except for Equation 4 for developing countries, the test statistics cannot reject the null- hypothesis and it is decided that there is no relationship between the series. That is, there is a relationship at the $10 \%$ significance level for developed countries.

Based on the findings, group statistics are taken into consideration since there is heterogeneity in estimation equations. As a result, supporting the Pedroni test results, it has been concluded that there is a co-integration relationship for both developed and developing country groups.

\section{LONG-RUN COEFFICIENTS}

There are many methods in the literature to estimate the long-term impact of the carbon emission caused by the transport sector and the innovation level for both developed and developing countries in the Mediterranean countries. In addition to the co-integration relationship for estimation equations, there is heterogeneity in the estimation equations. Since there is no cross-section dependency in this study, Group Mean FMOLS, Group Mean DOLS, and DFE (Dynamic Fixed Effect) test that do not take the cross-section dependency into account and take heterogeneous sections into account are used. 
In the FMOLS estimator, the long-term covariance matrix is allowed to vary according to cross-sections. FMOLS estimator is shown in Equation (26).

$$
\hat{\beta}_{F M O L S}-\beta=\left[\sum_{i=1}^{N} \hat{L}_{\varepsilon_{i}}^{-2} \sum_{t=1}^{T}\left(X_{i t}-\bar{X}_{i}\right)^{2}\right]^{-1} \sum_{i=1}^{N} \hat{L}_{u_{i}}^{-1} \hat{L}_{\varepsilon_{i}}^{-1}\left[\sum_{t=1}^{T}\left(X_{i t}-\bar{X}_{i}\right) Y_{i t}^{*}-T \hat{\gamma}_{i}\right]
$$

Equation (26) makes an assumption of homogeneity for horizontal sections. Group Mean FMOLS estimator, which takes heterogeneity into account, is equal to the mean of FMOLS estimators. The Group Mean - FMOLS estimator is shown in Equation (27).

$\hat{\beta}_{G M F M O L S}=N^{-1}\left[\sum_{i=1}^{N}\left(\sum_{t=1}^{T}\left(X_{i t}-\bar{X}_{i}\right)^{2}\right)\right]^{-1}\left[\sum_{t=1}^{T}\left(X_{i t}-\bar{X}_{i}\right) Y_{i t}^{*}-T \hat{\gamma}_{i}\right]$

The $t$ statistics of the Group Mean FMOLS estimator is shown in Equation (28).

$\bar{t}=\frac{1}{\sqrt{N}} \sum_{i=1}^{N} \hat{L}_{u i}^{-1}\left[\sum_{t=1}^{T}\left(X_{i t}-\bar{X}_{i}\right)^{2}\right]^{-1 / 2}\left[\sum_{t=1}^{T}\left(X_{i t}-\bar{X}_{i}\right) Y_{i t}^{*}-T \hat{\gamma}_{i}\right]$

(28)

Kao and Chiang (2000) proposed the DOLS (Dynamic OLS) estimator for estimating cointegrated regression equations and obtaining coefficients. The dynamic OLS estimation equation is seen in Equation (28).

$y_{i t}=\alpha_{i}+\beta x_{i t}+\sum_{j=q 1}^{j=q 2} c_{i j} \Delta x_{i t-j}+V_{i t}$

In Equation (29), $c_{i j}$ shows the delayed values of the predecessors and successors. DOLS coefficient is obtained from Equation (30).

$\hat{\beta}_{D O L S}=\left[\sum_{i=1}^{N} \sum_{t=1}^{T} q_{i t} q_{i t}^{\prime}\right]^{-1}\left[\sum_{i=1}^{N} \sum_{t=1}^{T} q_{i t} \hat{y}_{i t}^{*}\right]$

However, Equation (30) makes an assumption of homogeneity between sections. $q_{i t}$ is a vector of explanatory variables. In this study, the estimation equations are heterogeneous. Pedroni (2001) has included the average values for each cross-section in Equation (29), taking the heterogeneity into account. Thus, the group estimator method has been applied to the DOLS method. The Group Mean - DOLS estimator is shown in Equation (31).

$\hat{\beta}_{D O L S}=\frac{1}{N} \sum_{i=1}^{N}\left\{\left(\sum_{t=1}^{T} q_{i t} q_{i t}^{\prime}\right)^{-1} \sum_{t=1}^{T} q_{i t} \hat{y}_{i t}^{*}\right\}$

Group Mean FMOLS and Group Mean DOLS test results are shown in Table 


\begin{tabular}{|c|c|c|c|c|c|c|c|c|c|c|c|c|c|c|c|c|c|}
\hline \multirow{3}{*}{ Variables } & \multirow{3}{*}{$\begin{array}{l}\text { Coef. / } \\
\text { Prob. }\end{array}$} & \multicolumn{8}{|c|}{ DEVELOPED COUNTRIES } & \multicolumn{8}{|c|}{ DEVELOPING COUNTRIES } \\
\hline & & \multicolumn{4}{|c|}{ FMOLS } & \multicolumn{4}{|c|}{ DOLS } & \multicolumn{4}{|c|}{ FMOLS } & \multicolumn{4}{|c|}{ DOLS } \\
\hline & & Eq.1 & Eq. 2 & Eq.3 & Eq.4 & Eq.1 & Eq. 2 & Eq.3 & Eq.4 & Eq.1 & Eq. 2 & Eq.3 & Eq.4 & Eq.1 & Eq. 2 & Eq.3 & Eq.4 \\
\hline \multirow[t]{2}{*}{ EC } & Coef. & 1.205 & 0.181 & 1.344 & 0.271 & -13.227 & 1.059 & -3.952 & 1.016 & 0.591 & 0.434 & 1.005 & 0.829 & 1.042 & 1.375 & 1.413 & 2.417 \\
\hline & Prob. & 0.000 & 0.553 & 0.000 & 0.428 & 0.004 & 0.053 & 0.163 & 0.056 & 0.000 & 0.001 & 0.000 & 0.000 & 0.000 & 0.000 & 0.000 & 0.000 \\
\hline \multirow[t]{2}{*}{ LNGDPPC } & Coef. & 0.204 & -7.305 & 0.118 & -7.264 & 0.026 & -0.415 & -0.015 & -0.459 & 0.194 & -0.022 & 0.228 & 0.925 & 0.185 & -7.196 & 0.278 & -4.742 \\
\hline & Prob. & 0.000 & -0.022 & 0.012 & 0.042 & 0.872 & 0.924 & 0.920 & 0.911 & 0.000 & 0.976 & 0.000 & 0.142 & 0.010 & 0.000 & 0.000 & 0.001 \\
\hline \multirow[t]{2}{*}{ LNGDPPC2 } & Coef. & - & 0.367 & - & 0.361 & - & 0.031 & - & 0.030 & - & 0.009 & - & -0.046 & - & 0.425 & - & 0.300 \\
\hline & Prob. & - & 0.018 & - & 0.037 & - & 0.884 & - & 0.882 & - & 0.829 & - & 0.231 & - & 0.000 & - & 0.000 \\
\hline \multirow[t]{2}{*}{ LNTRADE } & Coef. & -0.232 & -0.279 & -0.300 & -0.341 & -1.309 & -0.210 & -1.018 & -0.328 & -0.083 & -0.168 & 0.062 & -0.052 & 0.033 & -0.287 & 0.307 & 0.203 \\
\hline & Prob. & 0.000 & 0.000 & 0.000 & 0.000 & 0.004 & 0.040 & 0.050 & 0.001 & 0.144 & 0.003 & 0.219 & 0.324 & 0.701 & 0.001 & 0.000 & 0.159 \\
\hline \multirow[t]{2}{*}{ LNU } & Coef. & -2.182 & -1.126 & -3.056 & -1.473 & 8.458 & 0.236 & 4.802 & 0.954 & 1.127 & 1.058 & 1.086 & 1.014 & 0.626 & -0.717 & 1.352 & 0.069 \\
\hline & Prob. & 0.133 & 0.377 & 0.115 & 0.410 & 0.001 & 0.677 & 0.055 & 0.061 & 0.000 & 0.000 & 0.000 & 0.000 & 0.042 & 0.108 & 0.001 & 0.817 \\
\hline \multirow[t]{2}{*}{ LNFD } & Coef. & -0.050 & -0.050 & -0.108 & -0.077 & 0.338 & -0.066 & 0.020 & -0.034 & -0.022 & -0.027 & -0.048 & -0.046 & 0.086 & 0.030 & -0.027 & 0.029 \\
\hline & Prob. & 0.400 & 0.421 & 0.118 & 0.322 & 0.047 & 0.475 & 0.878 & 0.658 & 0.684 & 0.576 & 0.138 & 0.186 & 0.349 & 0.655 & 0.667 & 0.687 \\
\hline \multirow[t]{2}{*}{ LNPAT } & Coef. & 0.123 & 0.040 & - & - & -0.088 & 0.050 & - & - & 0.002 & -0.028 & - & - & -0.039 & -0.045 & - & - \\
\hline & Prob. & 0.004 & 0.210 & - & - & 0.578 & 0.560 & - & - & 0.913 & 0.054 & - & - & 0.063 & 0.001 & - & - \\
\hline \multirow[t]{2}{*}{ LNTM } & Coef. & - & - & 0.133 & 0.098 & - & - & 0.413 & 0.163 & - & - & 0.043 & 0.016 & - & - & 0.063 & 0.153 \\
\hline & Prob. & - & - & 0.016 & 0.029 & - & - & 0.234 & 0.007 & - & - & 0.363 & 0.730 & - & - & 0.375 & 0.116 \\
\hline
\end{tabular}


Table 6 shows FMOLS results for developed countries. Based on the results obtained from equation 1, which includes the patent variable as an indicator of innovation, it is observed that energy consumption, per capita income, and innovation have a positive effect on carbon emissions. On the other hand, trade openness reduces carbon emissions. The effects of urban population and financial development are not statistically significant. When Equation 2 is analyzed, it is seen that per capita income has a negative effect on carbon emission up to a certain level, after this certain level it has a positive effect on carbon emission. This result does not support the reverse U shape assumed by the Kuznets hypothesis. In other words, this result indicates that the Kuznets hypothesis is invalid. In the context of the quadratic equation, innovation does not have a statistically significant effect on carbon emissions.

Similarly, energy consumption, urban population, and financial development do not seem to have a statistically significant effect on carbon emissions. On the other hand, trade volume decreases carbon emissions. In equations 3 and 4 using the trademark variable as the innovation variable, it is observed that innovation has a positive effect on carbon emission. Similarly, it is indicated that the Kuznets hypothesis is not valid for the quadratic function. In Equation 3, energy consumption and per capita income positively affect carbon emissions, while trade openness negatively affects. Energy consumption in Equation 4 is not statistically significant. Openness negatively affects carbon emissions. Urban population and Financial development are not statistically significant in equations 3 and 4.

The Group Mean DOLS results for developed countries indicated that energy consumption has a statistically significant negative effect only for equation 1 at the $5 \%$ significance level. For all estimation equations, it is shown that the per capita income and the square of the per capita income are not statistically significant. Trade openness has a statistically significant negative effect on carbon emission for each equation. The increase in the urban population increases carbon emissions. However, this effect is not statistically significant for equation 2. Financial development positively affects carbon emission in a statistically significant way only for equation 1. Finally, according to DOLS model results, the patent increase does not affect carbon emission, while trademark increase increases carbon emission for equation 4.

The FMOLS results for developing countries indicated that for equation 1, energy consumption, per capita income, and urban population growth have an increasing effect on carbon emissions. Trade openness and financial development do not affect carbon emissions. It was concluded that the level of innovation, which was the focus of this study, also did not affect carbon emissions. When the results obtained from Equation 2 are analyzed, energy consumption and urban population increase positively affect carbon emission, while increasing trade openness affects carbon emission negatively. For quadratic equation 2, per capita income and square of per capita income and financial development have no effect on carbon emissions. However, the increase in innovation has a negative effect on carbon emission at the $10 \%$ significance level. When the results obtained from Equation 3 are examined, energy consumption, per capita income, and urban population have an increasing effect on carbon emissions. On the other hand, trade openness and financial development do not have any effect on carbon emissions. In Equation 3 and 4, innovation does not seem to have any impact on carbon emissions. According to the results obtained from Equation 4, income per capita, the square of per capita income, trade openness, and financial development do not affect carbon emissions, while the increase in urban population affects carbon emissions positively.

Finally, according to the DOLS results for developing countries, for equations 1 and 2, for which the patent is an innovation indicator, the increase in innovation reduces carbon 
emissions. However, for equations 3 and 4, where the trademark variable is an indicator of innovation, it seems that innovation does not have an effect on carbon emissions. Energy consumption has a positive effect on carbon emissions for all equations. For Equation 1, while per capita income and urban population affect carbon emissions positively, trade deficit and financial deepening do not affect carbon emissions. In Equation 2, the increase in per capita income negatively affects the carbon emission, while the per capita income increase has a positive effect on the carbon emission after a certain level. While there is no statistically significant effect of financial deepening on the urban population, the trade deficit affects carbon emissions negatively. For Equation 3, per capita income, trade deficit, and the urban population positively affect carbon emissions, whereas financial deepening does not have a statistically significant effect on carbon emission. Finally, for equation 4, per capita income affects carbon emissions negatively, while per capita income after a certain threshold value affects carbon emissions positively. Trade openness, urban population, and financial deepening do not have any impact on carbon emissions.

As a result, evidence has been reached in our study that the Kuznets hypothesis is not valid. For developing countries, if the increase in innovation level is caused by the increase in patents, it has a negative effect on carbon emissions from transportation. However, the trademark increase does not have a statistically significant effect on carbon emissions. The test results for developed countries indicated that both the patent increase and the trademark increase have a positive effect on the carbon emission.

\section{CONCLUSION}

In this study, the impact of innovation on carbon emissions originating from the transportation sector is analyzed in the Mediterranean countries. Considering the IMF (2019) report, Mediterranean countries are divided into two groups as developed and developing countries. 8 developing countries whose data can be accessed; Albania, Algeria, Bosnia and Herzegovina, Croatia, Egypt, Morocco, Tunisia and Turkey, and 6 developed countries as Cyprus, France, Greece, Israel, Italy, Spain. The analysis period has been determined as 1997-2017 for developing countries and 2003-2017 for developed countries, depending on the availability of data.

In our study, patent applications and trademark applications, which are frequently used in the literature, were used as innovation indicators. The estimation equations for each innovation indicator were created both linearly and quadratic linearly to test the Kuznets hypothesis. Hence, 4 equations were used in total. The results obtained from our study did not provide evidence that the Kuznets hypothesis is valid. For developing countries, the increase in the level of innovation has a negative impact on carbon emissions from transport if the innovation results from the increase in patents. However, the trademark increase does not have a statistically significant effect on carbon emissions. When the results for developed countries are examined, it is seen that both the patent increase and the trademark increase have a positive effect on the carbon emission. As the development level of the countries increases, the demand for personal vehicles also increases. In the developed countries, the income per capita is high enough to have own car. Therefore, as Erdoğan et al. (2020) pointed, although a relative decrease in $\mathrm{CO}_{2}$ emissions from vehicles is observed through energy saving innovation technologies, having more personal vehicles and driving more bring more energy consumption in the developed Mediterranean countries in spite of increasing energy efficiency in transportation technologies. Hence, to decrease the $\mathrm{CO}_{2}$ emissions in the Mediterranean countries, environment-friendly innovation technologies should be improved. 
However, parallel to Rennings (2000) findings, it should be noted that new model of environment-friendly vehicles need infrastructure investments for adaptation and diffusion. Therefore convenient infrastructure investments should be initiated such as having widespread charging stations and technological improvement to compete with their conventional counterparts. Besides, conventional car owners should be encouraged to consume less pollutive fuels and government should initiate regulations and measures to control low quality polluting fuels. Furthermore, environment friendly vehicles such as electric vehicles should be widespread through tax incentives and other supports.

Annex 1: PANIC Unit Root Test

\begin{tabular}{|c|c|c|c|c|c|c|c|c|}
\hline \multirow{4}{*}{ Tests } & \multicolumn{8}{|c|}{ DEVELOPING COUNTRIES } \\
\hline & \multicolumn{2}{|c|}{ Intercept } & \multicolumn{2}{|c|}{ Int\&Trend } & \multicolumn{2}{|c|}{ Intercept } & \multicolumn{2}{|c|}{ Int\&Trend } \\
\hline & \multicolumn{4}{|l|}{ EC } & \multicolumn{4}{|c|}{ LNGDPPC } \\
\hline & Stat. & $\mathrm{p}$-value & Stat. & $\mathrm{p}$-value & Stat. & $\mathrm{p}$-value & Stat. & p-value \\
\hline $\mathrm{Pa}$ & -0.708 & 0.240 & -1.730 & 0.042 & 1.880 & 0.970 & 0.551 & 0.709 \\
\hline $\mathrm{Pb}$ & -0.537 & 0.296 & -1.340 & 0.090 & 2.555 & 0.995 & 0.630 & 0.736 \\
\hline \multirow[t]{2}{*}{ PMSB } & -0.589 & 0.278 & -0.848 & 0.198 & 2.219 & 0.987 & 0.712 & 0.762 \\
\hline & \multicolumn{4}{|l|}{ LNTM } & \multicolumn{4}{|l|}{ LNPAT } \\
\hline $\mathrm{Pa}$ & -4.437 & 0.000 & -1.412 & 0.079 & -1.061 & 0.144 & -0.570 & 0.284 \\
\hline $\mathrm{Pb}$ & -2.165 & 0.015 & -1.159 & 0.123 & -0.846 & 0.199 & -0.515 & 0.303 \\
\hline \multirow[t]{2}{*}{ PMSB } & -1.382 & 0.084 & -0.775 & 0.219 & -0.480 & 0.316 & -0.352 & 0.363 \\
\hline & \multicolumn{4}{|c|}{ LNTRADE } & \multicolumn{4}{|c|}{ LNTCO2 } \\
\hline $\mathrm{Pa}$ & -3.520 & 0.000 & -0.559 & 0.288 & -1.869 & 0.031 & 1.047 & 0.852 \\
\hline $\mathrm{Pb}$ & -1.815 & 0.035 & -0.508 & 0.306 & -1.549 & 0.061 & 1.445 & 0.926 \\
\hline \multirow[t]{2}{*}{ PMSB } & -1.229 & 0.110 & -0.383 & 0.351 & -0.561 & 0.288 & 1.947 & 0.974 \\
\hline & \multicolumn{4}{|c|}{ LNGDPPC2 } & \multicolumn{4}{|c|}{ LNURBAN } \\
\hline $\mathrm{Pa}$ & 1.966 & 0.975 & 0.220 & 0.587 & -4.528 & 0.000 & -0.989 & 0.161 \\
\hline $\mathrm{Pb}$ & 2.633 & 0.996 & 0.233 & 0.592 & -2.338 & 0.010 & -0.826 & 0.204 \\
\hline \multirow[t]{2}{*}{ PMSB } & 2.077 & 0.981 & 0.255 & 0.601 & -1.052 & 0.146 & -0.591 & 0.277 \\
\hline & \multicolumn{4}{|l|}{ LNFD } & & & & \\
\hline $\mathrm{Pa}$ & -3.556 & 0.000 & -1.333 & 0.091 & & & & \\
\hline $\mathrm{Pb}$ & -1.661 & 0.048 & -1.105 & 0.135 & & & & \\
\hline \multirow[t]{2}{*}{ PMSB } & -1.394 & 0.082 & -0.763 & 0.223 & & & & \\
\hline & \multicolumn{8}{|c|}{ DEVELOPED COUNTRIES } \\
\hline \multirow[t]{3}{*}{ Tests } & \multicolumn{2}{|c|}{ Intercept } & \multicolumn{2}{|c|}{ Int\&Trend } & \multicolumn{2}{|c|}{ Intercept } & \multicolumn{2}{|c|}{ Int\&Trend } \\
\hline & \multicolumn{4}{|l|}{$\mathrm{EC}$} & \multicolumn{4}{|l|}{ GDPPC } \\
\hline & Stat. & $\mathrm{p}$-value & Stat. & $\mathrm{p}$-value & Stat. & $\mathrm{p}$-value & Stat. & p-value \\
\hline $\mathrm{Pa}$ & 0.617 & 0.731 & -1.356 & 0.088 & -1.052 & 0.146 & -0.855 & 0.196 \\
\hline $\mathrm{Pb}$ & 20.497 & 1.000 & -1.225 & 0.110 & -64.530 & 0.000 & -0.826 & 0.204 \\
\hline PMSB & 1.792 & 0.963 & -0.544 & 0.293 & -0.491 & 0.312 & -0.239 & 0.406 \\
\hline & $\mathrm{TM}$ & & & & PAT & & & \\
\hline $\mathrm{Pa}$ & 0.752 & 0.774 & 1.544 & 0.939 & 1.420 & 0.922 & -1.706 & 0.044 \\
\hline $\mathrm{Pb}$ & 38.234 & 1.000 & 2.606 & 0.995 & 46.343 & 1.000 & -1.540 & 0.062 \\
\hline
\end{tabular}




\begin{tabular}{|c|c|c|c|c|c|c|c|c|}
\hline PMSB & 6.885 & 1.000 & 4.823 & 1.000 & 1.155 & 0.876 & -0.612 & 0.270 \\
\hline & \multicolumn{4}{|l|}{ TRADE } & \multicolumn{4}{|l|}{$\mathrm{TCO} 2$} \\
\hline $\mathrm{Pa}$ & -1.090 & 0.138 & -1.126 & 0.130 & -2.786 & 0.003 & -0.481 & 0.315 \\
\hline $\mathrm{Pb}$ & -50.177 & 0.000 & -1.065 & 0.143 & -81.928 & 0.000 & -0.485 & 0.314 \\
\hline \multirow[t]{2}{*}{ PMSB } & -0.069 & 0.473 & -0.387 & 0.349 & -0.871 & 0.192 & 0.004 & 0.502 \\
\hline & \multicolumn{4}{|l|}{ GDPPC2 } & \multicolumn{4}{|c|}{ URBAN } \\
\hline $\mathrm{Pa}$ & 0.773 & 0.780 & -0.080 & 0.468 & -1.090 & 0.138 & -1.443 & 0.075 \\
\hline $\mathrm{Pb}$ & 1.251 & 0.895 & -0.087 & 0.465 & -50.177 & 0.000 & -1.275 & 0.101 \\
\hline \multirow[t]{2}{*}{ PMSB } & 2.099 & 0.982 & 0.510 & 0.695 & -0.069 & 0.473 & -0.613 & 0.270 \\
\hline & FD & & & & & & & \\
\hline $\mathrm{Pa}$ & 1.569 & 0.942 & -1.468 & 0.071 & & & & \\
\hline $\mathrm{Pb}$ & 67.356 & 1.000 & -1.341 & 0.090 & & & & \\
\hline PMSB & 0.853 & 0.803 & -0.529 & 0.298 & & & & \\
\hline
\end{tabular}

\section{ETHICAL APPROVAL}

941 Dear Editor

942 I have the pleasure of submitting you a new manuscript entitled "A Comparative Analysis

943 of Relationship between Innovation and Transport Sector Carbon Emissions in 944 Developed and Developing Mediterranean Countries" authored by Nigar Demircan Çakar, 945 Ayfer Gedikli, Seyfettin Erdoğan and Durmuş Çağrı Yıldırım to be considered for publication 946 as a research article in your prestigious journal. We confirm that this work is original and has 947 not been published elsewhere nor is it currently under consideration for publication elsewhere. 948 All authors listed have contributed sufficiently to the paper.

949

950 No conflict of interest, financial or other, exists.

951

952 As such this paper will be of interest to a broad readership including those interested in 953 economics, environmental/ecological economics and sustainable development.

954

955 Please address all correspondence concerning this manuscript to me at

956 ayfergedikli@yahoo.com

957 Thank you for your consideration of this manuscript.

958 Sincerely

959 Ayfer Gedikli 
962 AUTHORS' CONTRIBUTION

963 NDÇ: Data collection, theoretical background

964 AG: Theoretical background, literature and conclusion

965 SE: Econometric modelling and conclusion

966 DÇY: Econometric modelling

967

968

Ethical Approval

969

Not applicable

970 Consent to Participate

971 Not applicable

972 Consent to Publish

973 Not applicable

974 Competing Interests

975 The authors have no relevant financial or non-financial interests to disclose.

$976 \quad$ Funding

977 Not applicable

978 Availability of data and materials

979 The datasets generated and/or analysed during the current study are available in the U.S. 980 Energy Information Administration [https://www.eia.gov/totalenergy/data/browser/], in the 981 European Union Report- Fossil $\mathrm{CO}_{2}$ emissions of all world countries 982 [https://ec.europa.eu/jrc/en/publication/eur-scientific-and-technical-research-reports/fossil983 co2-emissions-all-world-countries-2020-report] and in the World Bank websites 984 [https://data.worldbank.org/].

REFERENCES

987 Álvarez-Herránza, A.; Balsalobreb, D.; Cantos, J. M.; Shahbaz, M. (2017). Energy 988 innovations-GHG emissions nexus: Fresh empirical evidence from OECD countries, Energy 989 Policy, 101, 90-100. 
Amri, F.; Bélaïd, F.; and Roubaud, R. (2018). Does technological innovation improve environmental sustainability in developing countries? Some evidence from Tunisia. The Journal of Energy and Development, 44, No. 1/2 (Autumn 2018 and Spring 2019), 41-60

Bai, J. and Ng, S., (2004). A PANIC attack on unit roots and co-integration. Econometrica, 74(4), 1127-1177.

Banister, D. (2005). Unsustainable transport, city transport in the new century. Routledge: Abingdon.

Broughel, J. and Thierer, A. (2019). Technological innovation and economic growth: A brief report on the evidence. Mercatus Research, Mercatus Center at George Mason University, Arlington, February 2019.

Chang, Y. (2002). Nonlinear IV unit root tests in panels with cross-section dependency. Journal of Econometrics, 110, 261-292

Danish (2019). Effects of information and communication technology and real income on $\mathrm{CO}_{2}$ emissions: The experience of countries along Belt and Road. Telematics and Informatics, 45,101300 .

Du, K.; Li, P.; and Yan, Z. (2019). Do green technology innovations contribute to carbon dioxide emission reduction? Empirical evidence from patent data. Technological Forecasting \& Social Change, 146, 297-303.

Du, H.; Chen, Z.; Peng, B.; Southworth, F.; and Ma, S. (2019). What drives $\mathrm{CO}_{2}$ emissions from the transport sector? A linkage analysis. Energy, 175, 195-204.

Erdoğan, S.; Yıldırım, D.Ç.; Gedikli, A. (2019). Investigation of causality analysis between economic growth and CO2 emissions: the case of BRICS - T countries. International Journal of Energy Economics and Policy 9 (6), 430-438.

Erdoğan, S.; Gedikli, A.; Yılmaz, A.D.; Haider, A. (2019). Investigation of energy consumption-Economic growth nexus: a note on MENA sample. Energy Reports, 5, 12811292.

Erdoğan, S.; Yıldırım, S.; Yıldırım, D. Ç.; and Gedikli, A. (2020). The effects of innovation on sectoral carbon emissions: Evidence from G20 countries. Journal of Environmental Management, 267, 110637.

Fan, F. and Lei, Y. (2016). Decomposition analysis of energy-related carbon emissions from the transportation sector in Beijing. Transportation Research Part D: Transport and Environment, 42, 135-145.

Fei, Q.; Rasiah, R.; and Shen, L. J. (2014). The clean energy-growth nexus with $\mathrm{CO}_{2}$ emissions and technological innovation in Norway and New Zealand. Energy and Environment, 25(8), 1323-1344. 
Georgatzi, V. V.; Stamboulis, Y.; and Vetsikas, A. (2020). Examining the determinants of $\mathrm{CO} 2$ emissions caused by the transport sector: Empirical evidence from 12 European countries. Economic Analysis and Policy, 65, 11-20.

Goulias, D. (2007). Development of high performance and innovative infrastructure materials. In Transport Science and Technology. Ed. K. G. Goulias, Elsevier, Oxford, 55-67.

Greening, L. A.; Greene, D. L.; and Difiglio, C. (2000). Energy efficiency and consumptionthe rebound effect-a survey. Energy Policy, 28, 389-401.

Guo, B.; Geng, Y.; Franke, B.; Hao, H.; Liu, Y.; and Chiu, A. (2014). Uncovering China's transport CO2 emission patterns at the regional level. Energy Policy, 74, 134-146.

Herring, H. and Roy, R. (2007). Technological innovation, energy efficient design and the rebound effect. Technovation, 27(4), April 2007, 194-203.

IEA (2009a). Transport, energy, and $\mathrm{CO}_{2}$, moving towards sustainability. France.

IEA (2009b). Transport, Energy and CO2. Report, October 2009.

IEA (2019a). CO2 emissions from fuel combustion by sector 2017. https://www.iea.org/dataand-statistics/charts/transport-sector-co2-emissions-by-mode-in-the-sustainable-development$\underline{\text { scenario-2000-2030 }}$

IEA (2019b). Transport sector $\mathrm{CO}_{2}$ emissions by mode in the Sustainable Development Scenario, 2000-2030, 22 November 2019. https://www.iea.org/data-andstatistics/charts/transport-sector-co2-emissions-by-mode-in-the-sustainable-developmentscenario-2000-2030

IEA (2020a). Transport-Improving the sustainability of passenger and freight transport. https://www.iea.org/topics/transport

IEA (2020b). Global energy review 2020. April 2020. https://www.iea.org/reports/globalenergy-review-2020/global-energy-and-co2-emissions-in-2020

IMF (2019). World Economic Outlook, October 2019: Global Manufacturing Downturn, Rising Trade Barriers. International Monetary Fund. Research Dept., Washington DC:USA.

Irandoust, M. (2016). The renewable energy-growth nexus with carbon emissions and technological innovation: Evidence from the Nordic countries. Ecological Indicators, 69, 118-125.

Jiang, Y.; Zhou, Z.; and Liu, C. (2018). The impact of public transportation on carbon emissions: A panel quantile analysis based on Chinese provincial data. Environmental Science and Pollution Research, 26, 4000-4012.

Jin, L.; Duan, K.; and Tang, X. (2018). What is the relationship between technological innovation and energy consumption? Empirical analysis based on provincial panel data from China. Sustainability, 10(145), 9 January 2018, 1-13. 
Johnstone, N.; Haščič, I. and Popp, D. (2010). Renewable energy policies and technological innovation: Evidence based on patent counts. Environmental and Resource Economics, 45, 133-155(2010)

Kahouli, B. (2018). The causality link between energy electricity consumption, $\mathrm{CO}_{2}$ emissions, R\&D stocks and economic growth in Mediterranean countries (MCs). Energy, $145,388-399$.

Kao, C., \& Chiang, M. (2000). Nonstationary panels, co-integration in panels and dynamic panels. On the estimation and inference of a cointegrated regression in panel data. Amsterdam: Elsevier.

Khan, A. N.; En, X.; Raza, M. Y.; Khan, N. A.; and Ali, A. (2020). Sectorial study of technological progress and $\mathrm{CO} 2$ emission: Insights from a developing economy. Technological Forecasting \& Social Change, 151, 119862.

Khattak, S. I.; Ahmad, M.; Khan, Z.; and Khan, A. (2020). Exploring the impact of innovation, renewable energy consumption, and income on $\mathrm{CO} 2$ emissions: New evidence from the BRICS economies. Environmental Science and Pollution Research, April 2020, 27(12), 13866-13881.

Koçak, E. and şentürk Ulucak, Z. (2019). The effect of energy R\&D expenditures on $\mathrm{CO}_{2}$ emission reduction: Estimation of the STIRPAT model for OECD countries. Environmental Science and Pollution Research, 26, 14328-14338.

Lemoine, D. (2019). General equilibrium rebound from energy efficiency innovation. NBER Working Paper, No. 25172, September 2019.

Le Quéré, C.; Jackson, R. B.; Jones, M. W.; Smith, A. J. P.; Abernethy, S.; Andrew, R. M.; ...; Peter, G. P. (2020). Temporary reduction in daily global $\mathrm{CO}_{2}$ emissions during the COVID-19 forced confinement. 19 May 2020. Nature Climate Change, 10, 647-653.

Li, H.; Lu, Y.; Zhang, J.; and Wang, T. (2013). Trends in road freight transportation carbon dioxide emissions and policies in China. Energy Policy, 57, 99-106.

Maradana, R. P.; Pradhan, R. P.; Dash, S.; Gaurav, K.; Jayakumar, M.; and Chatterjee, D. (2017). Does innovation promote economic growth? Evidence from European countries. Journal of Innovation and Entrepreneurship, 6(1), 1-23.

Mensah, C. N.; Long, X.; Boamah, K. B.; Bediako, I. A.; Dauda, L.; and Salman, M. (2018). The effect of innovation on CO2 emissions of OECD countries from 1990 to 2014. Environmental Science and Pollution Research, 25, 29678-29698.

Moon, R. and Perron, B (2004) Testing for a unit root in panels with dynamic factors. Journal of Econometrics, 122, 81-126.

Muntean, M., Guizzardi, D., Schaaf, E., Crippa, M., Solazzo, E., Olivier, J.G.J. and Vignati, E. (2018). Fossil $\mathrm{CO}_{2}$ emissions of all world countries - 2018 Report. EUR 29433 EN, Publications Office of the European Union, Luxembourg. 
Nguyen, T. T.; Pham, T. A. T.; and Tram, H. T. X. (2020). Role of information and communication technologies and innovation in driving carbon emissions and economic growth in selected G-20 countries. Journal of Environmental Management, 261, 110162.

O'Connell, P.G.J. (1998). The overvaluation of purchasing power parity. Journal of International Economics, 44(1), 1-19.

Pece, A. M.; Simona, O. E. O.; and Salisteanu, F. (2015). Innovation and economic growth: An empirical analysis for CEE countries. Procedia Economics and Finance, 26, 461-467.

Pedroni, P. (2001). Purchasing Power Parity Tests in Cointegrated Panels. Department of Economics Working Papers 2001-01, Department of Economics, Williams College.

Pedroni, P. (2004). Panel cointegration: Asymtotic and finite sample properties of pooled time series tests with an application to the PPP hypothesis. Econometric Theory, 20, 597-625.

Pesaran, M. H. (2004). General diagnostic tests for cross-section dependence in panels. Cambridge Working Papers in Economics, 435.

Pesaran, M. H. (2007). A simple unit root test in the presence of cross-section dependence. Journal of Applied Economics, 22, 265-312.

Pesaran, M. H. and Yamagata, T. (2008). Testing Slope Homogeneity in Large Panels. Journal of Econometrics, 142 (1), 50-93.

Pesaran, M. H. and Yamagata, T. (2008). Testing Slope Homogeneity in Large Panels. Journal of Econometrics, 142 (1), 50-93.

Petrovic, P. and Lobanov, M. M. (2020). The impact of R\&D expenditures on $\mathrm{CO}_{2}$ emissions: Evidence from sixteen OECD countries. Journal of Cleaner Production, 248, 119187.

Rennings, K. (2000). Redefining innovation-eco-innovation research and the contribution from ecological economics. Ecological Economics, 32, 319-332.

Ritchie, H. and Roser, M. (2020). Emissions by sectors. Our World in Data. https://ourworldindata.org/emissions-by-sector\#annual-greenhouse-gas-emissions-by-sector

Roger, E. M. (1983). Diffusion of innovation. Third edition. The Free Press. New York.

Rosenberg, N. (2004). Innovation and economic growth. OECD. https://www.oecd.org/cfe/tourism/34267902.pdf

Rowland, F. S.; Bruce, J. P; Graedel, T. E.; Reck, R. A.; Sperling, D.; and Waltn, C. M. (1998). Atmospheric change and the North American transportation sector: Summary of a trilateral workshop. Incidental Report No. IR98-1, The Royal Society of Canada, 1-24.

Samargandi, N. (2017). Sector value addition, technology and $\mathrm{CO}_{2}$ emissions in Saudi Arabia. Renewable and Sustainable Energy Reviews, 78, 868-877.

Schumpeter, J. A. (2000). Entrepreneurship as innovation. The University of Illinois at Urbana-Champaign's Academy for Entrepreneurial Leadership Historical Research Reference in Entrepreneurship, Available at SSRN: https://ssrn.com/abstract=1512266. 
Shahbaz, M.; Raghutla, C.; Song, M.; Zameer, H.; and Jiao, Z. (2020). Public-private partnership investment in energy as new determinant of $\mathrm{CO} 2$ emissions: The role of technological innovations in China. Energy Economics, 86, 104664.

Su, H.-N.; Moaniba, I. M. (2017). Does innovation respond to climate change? Empirical evidence from patents and greenhouse gas emissions. Technological Forecasting and Social Change, 122, 49-62.

Swamy, P. A. V. B. (1970). Efficient inference in a random coefficient regression model. Econometrica, 38, 311-323.

Teter, J.; Tattini, J.; and Petropoulos, A. (2020). Tracking transport 2020- More efforts needed. Tracking Report, IEA, May 2020. https://www.iea.org/reports/tracking-transport$\underline{\text { 2020\# }}$

Ulku, H. (2004). R\&D, Innovation, and Economic Growth: An Empirical Analysis. IMF Working Paper, WP/04/185, September 2004.

UNCED (1992). Sustainabel development goals platform, Agenda 21. https://sustainabledevelopment.un.org/outcomedocuments/agenda21

The United States Environmental Protection Agency (EPA) (2019). Source of greenhouse emissions, transportation sector emissions. https://www.epa.gov/ghgemissions/sourcesgreenhouse-gas-emissions\#carbon-dioxide

Wang, Z. and He, W. (2017). $\mathrm{CO}_{2}$ emissions efficiency and marginal abatement costs of the regional transportation sectors in China. Transportation Research Part D: Transport and Environment, 50, January 2017, 83-97.

Wen, Q.; Chen, Y.; Hong, J.; Chen, Y.; Ni, D.; and Shen, Q. (2020). Spillover effect of technological innovation on $\mathrm{CO}_{2}$ emissions in China's construction industry. Building and Environment, 171, 106653.

Westerlund, J. (2008). "Panel Co-integration Tests of the Fisher Effect". Journal of Applied Econometrics 23(2), 193-223.

World Bank, https://databank.worldbank.org/home.aspx.

Zhang, Y.-J..; Peng, Y.-L.; Ma, C.-Q.; and Shen, B. (2017) Can environmental innovation facilitate carbon emissions reduction? Evidence from China. Energy Policy, 100, 18-28.

Zhou, G.; Chung, W.; and Zhang, X. (2013). A study of carbon dioxide emissions performance of China's transport sector. Energy, 50, 302-314.

Zhu, C. and Du, W. (2019). A research on driving factors of carbon emissions of road transportation industry in six Asia-Pacific countries based on the LMDI decomposition method. Energies, 12, 4152, 1-19. 
Figures

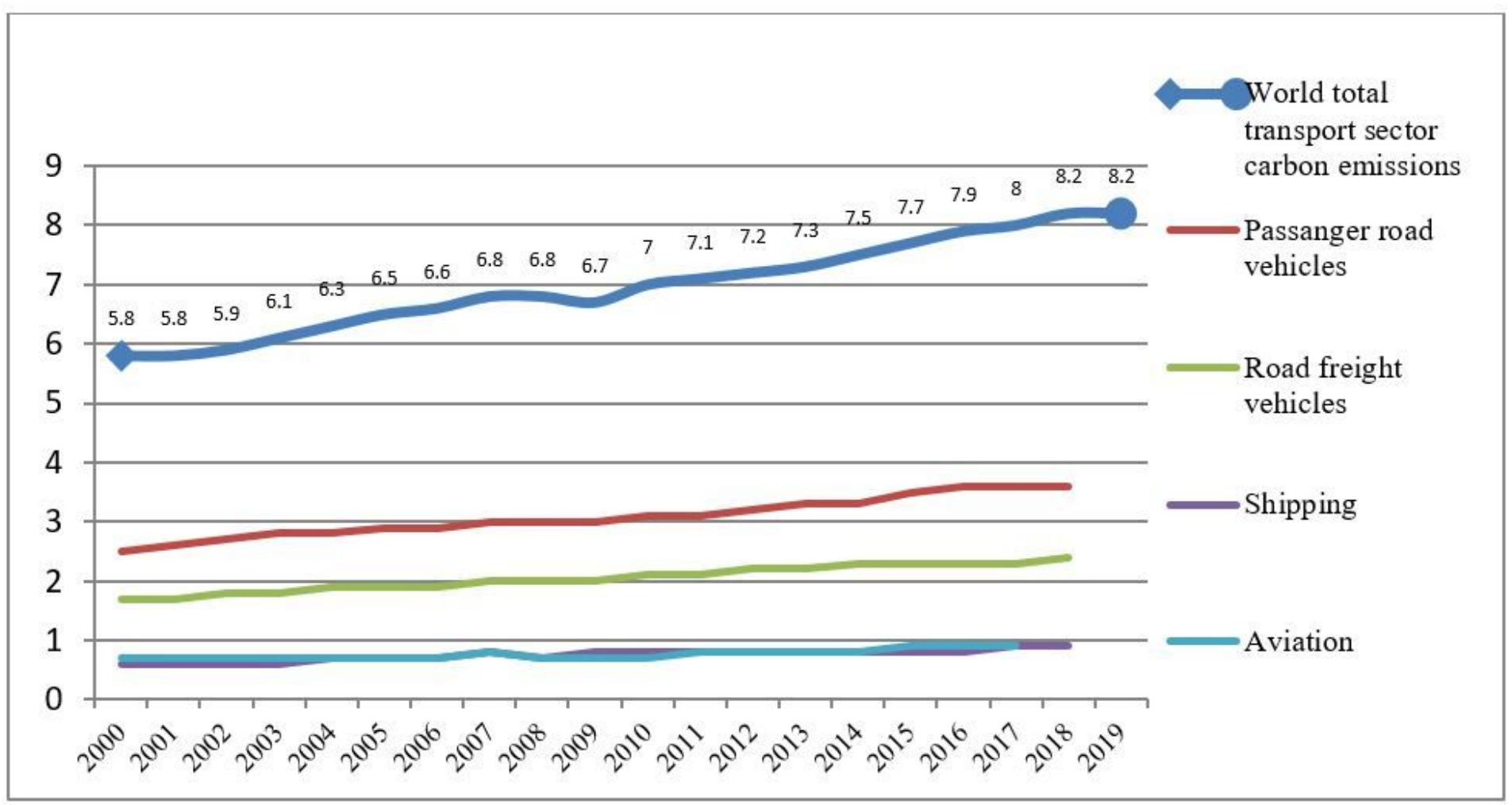

\section{Figure 1}

Global Transport Sector Carbon Emissions (Gt, 2000-2019) Source: Teter, Tattini and Petropoulos (2020); IEA (2019b)

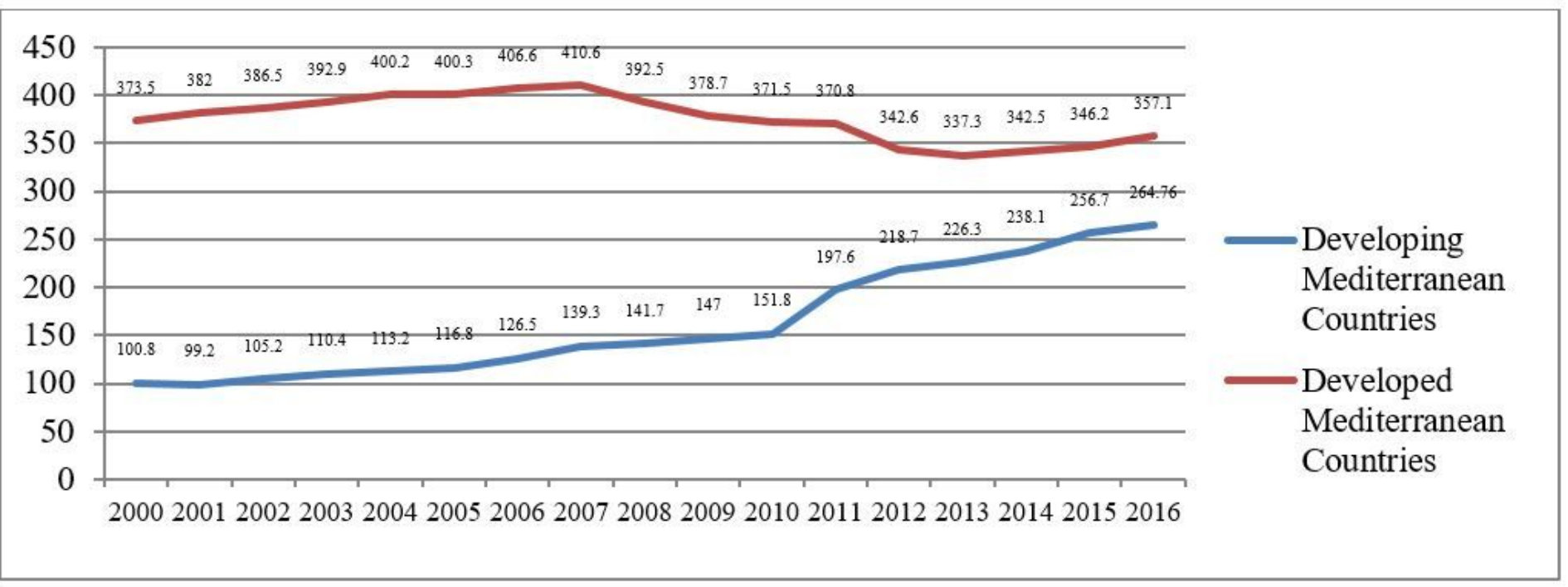

Figure 2 
Developed and Developing Mediterranean Countries Carbon Emissions from the Transportation Sector (million tones, 2000-2016) Source: Authors' own calculations from Ritchie and Roser (2020) Developing Mediterranean Countries: Turkey, Albania, Bosnia and Herzegovina, Croatia, Algeria, Tunisia, and Morocco Developed Mediterranean Countries: Israel, Italy, France, Spain, Greece, Cyprus

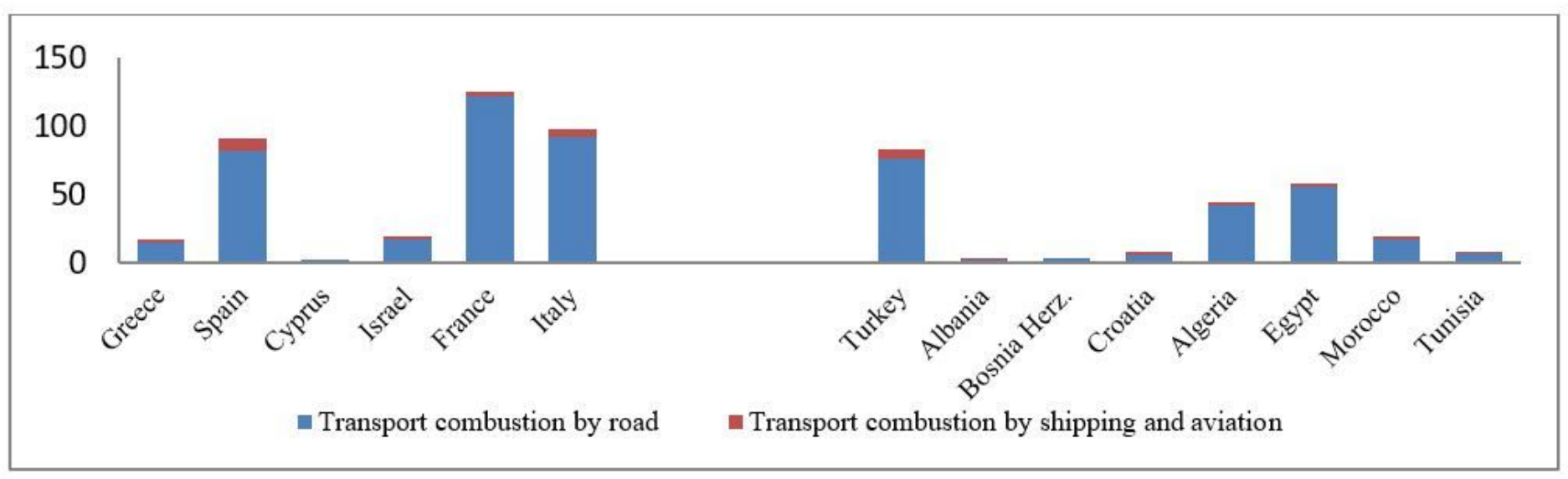

\section{Figure 3}

Developed and Developing Mediterranean Countries Carbon Emissions from Transport (Road and Shipping-Aviation) (2017, million tones) Source: IEA (2019a)

\section{Supplementary Files}

This is a list of supplementary files associated with this preprint. Click to download.

- floatimage1.png 